\title{
Inequalities in medicine use in Central Eastern Europe: an empirical investigation of socioeconomic determinants in eight countries
}

Sabine Vogler ${ }^{1}$, August Österle ${ }^{2}$ and Susanne Mayer ${ }^{3^{*}}$

\begin{abstract}
Background: Equitable access to essential medicines is a major challenge for policy-makers world-wide, including Central and Eastern European countries. Member States of the European Union situated in Central and Eastern Europe have publicly funded pharmaceutical reimbursement systems that should promote accessibility and affordability of, at least essential medicines. However, there is no knowledge whether socioeconomic inequalities exist in these countries. Against this backdrop, this study analyses whether socioeconomic determinants influence the use of prescribed and non-prescribed medicines in eight Central and Eastern European countries (Bulgaria, Czech Republic, Hungary, Latvia, Poland, Romania, Slovenia, Slovakia). Further, the study discusses observed (in)equalities in medicine use in the context of the pharmaceutical policy framework and the implementation in these countries.
\end{abstract}

Methods: The study is based on cross-sectional data from the first wave of the European Health Interview Survey (2007-2009). Multivariate logistic regression analyses were carried out to determine the association between socioeconomic status (measured by employment status, education, income; controlled for age, gender, health status) and medicine use (prescribed and non-prescribed medicines). This was supplemented by a pharmaceutical policy analysis based on indicators in four policy dimensions (sustainable funding, affordability, availability and accessibility, and rational selection and use of medicines).

Results: Overall, the analysis showed a gradient favouring individuals from higher socioeconomic groups in the consumption of non-prescribed medicines in the eight surveyed countries, and for prescribed medicines in three countries (Latvia, Poland, Romania). The pharmaceutical systems in the eight countries were, to varying degrees, characterized by a lack of (public) funding, thus resulting in high and growing shares of private financing (including co-payments for prescribed medicines), inefficiencies in the selection of medicines into reimbursement and limitations in medicines availability.

Conclusion: Pharmaceutical policies aiming at reducing inequalities in medicine use require not only a consideration of the role of co-payments and other private expenditure but also adequate investment in medicines and transparent and clear processes regarding the inclusion of medicines into reimbursement.

Keywords: Medicines, Access, Use, Inequalities, Education, Income, Affordability, Availability, Co-payments

\footnotetext{
* Correspondence: susanne.mayer@meduniwien.ac.at

${ }^{3}$ Department of Health Economics, Centre for Public Health, Medical

University of Vienna, Kinderspitalgasse 15/1, 1090 Vienna, Austria

Full list of author information is available at the end of the article
} 


\section{Background}

Ensuring equitable access to essential medicines is a major challenge for policy-makers. Essential medicines are those that satisfy the priority health care needs of the population and should be selected with due regard to disease prevalence, evidence on efficacy and safety, and comparative cost effectiveness. Essential medicines are intended to be available within the context of functioning health systems at all times, in adequate amounts, in the appropriate dosage forms, with assured quality, and at a price that the individual and the community can afford [1]. Countries have the responsibility to provide access to essential medicines while the implementation of the concept of essential medicines is intended to be flexible and adaptable to country specific situations [2].

The World Health Organization (WHO) has been promoting the concept of universal health coverage, arguing that timely access to health services, including medication, requires a well-functioning health financing system [3]. Related to pharmaceuticals, this means that, independently from the ownership of the suppliers (private or public suppliers and dispensaries), those medicines considered as essential in the national context are, at least partially, funded by the state, through a social health insurance system or a national health service.

Such reimbursement systems are in place in all Member States of the European Union (EU) where funding and reimbursement of medicines remains a national competence even if other areas (marketing authorization) have been harmonized [4]. This is also the case of the Central and Eastern European countries (CEECs) that are members of the EU. As of 2015, this is a total of eleven countries: Czech Republic, Estonia, Hungary, Latvia, Lithuania, Poland, Slovenia and Slovakia (acceding to the EU in 2004); Bulgaria and Romania (joining the EU in 2007); and Croatia which has been an EU Member State since mid-2013.

From the 1990s, the CEECs have changed from highly centralised and hospital-centred Semaskho systems towards social insurance systems with varying degrees of state centeredness and liberal market elements [5, 6]. In terms of pharmaceutical policies, the CEECs departed from the former principle of free medication for the entire population, starting to differentiate between medicines that should either be fully or partially reimbursed by the health system and introducing co-payment schemes for out-patient medicines [7-10].

In the new millennium, all these countries had positive lists, i.e. lists of medicines that may be prescribed at the expense of a third party payer (corresponding to the essential medicines lists concept). However, there are indications that the lists of (co-)funded medicines in the CEECs were smaller compared to those in the Western, Northern and Southern EU Member States [9, 10].
Further, medicines included in the positive lists were not necessarily $100 \%$ funded since medicines whose therapeutic benefit was assessed to be lower were funded partially, with the remainder to be paid by out-patients in out-patient care [8-10]. In order to ensure financial sustainability for medicines, the CEECs implemented, to a greater or lesser extent, several of the policy options available: They applied price regulation for medicines, at least for those (partially) funded by the state at exfactory price (manufacturer price) as well as at wholesale and retail price level (regulating the maximum allowed profits for distributors and dispensaries) [8-10]. In addition, lower priced generics were more widely used in the CEECs compared to other EU Member States: this might be attributable to a traditionally strong role of local generic industry, but also to demand-side measures such as encouraging doctors to prescribe by International Non-Proprietary Name (INN) and allowing pharmacists to substitute prescribed brands by generics (generic substitution) $[11,12]$.

Still, investment in health care, including medicines, is known to be lower in the Central and Eastern European region, and several CEECs have been struggling with limited health budgets, making cost-containment a major policy concern $[6,7,13]$. Consequently, out-of-pocketpayments, including informal payments [14-17], considerably increased. Respective austerity measures shifted the financial burden from the state to private households, with a potential risk that vulnerable population groups refrain from using health care services, including getting prescriptions filled and purchasing non-prescribed Over-theCounter (OTC) medicines [18].

At the same time, limited evidence is available regarding inequalities in medicine use. To our best knowledge, the socioeconomic determinants of medicine use in the CEECs have not yet been explored in detail. Exceptions include Geckova et al. [19], studying socioeconomic differences in health, including the use of prescribed and non-prescribed medicines, of adolescents in Slovakia in 1998, or Gorecka et al. [20] analysing as to whether a socioeconomic gradient existed in the use of (prescribed) cardiovascular medicines at district level in the Czech Republic for the years 1997-2000. Though not studying socioeconomic (in)equalities, the study by Baji et al. [21] is also relevant in this context: Concerns for socioeconomic inequalities were raised following the increase in out-of-pocket payments, including co-payments after the 2007 health care reform in Hungary.

Against this background, our study aims to analyse whether socioeconomic determinants influence medicine use, i.e. both use of prescribed medicines and nonprescribed medicines, in eight CEECs (Bulgaria, Czech Republic, Hungary, Latvia, Poland, Romania, Slovenia, Slovakia). Based on these findings, we discuss to what 
extent observed inequalities can potentially be explained by current pharmaceutical policies (or a lack of respective policies).

This article is thus first to study inequalities in medicine use in CEECs. To this end, we first present a brief review of the literature on inequalities in health care and, more specifically, medicine use, and, introduce our analytical framework. We perform a quantitative analysis of (in)equalities in medicine use based on household survey data from the first wave of the European Health Interview Survey (EHIS). The findings are interpreted in a policy analysis that follows the developed framework and uses information and research on national pharmaceutical systems.

\section{Addressing inequalities in medicine use}

Following the international literature, equitable access to and equitable use of health care is generally defined as access to and use of health care that is determined by health care need rather than any other criteria such as socioeconomic and demographic factors (e.g. income, education, sex or age) or the macro level institutional factors (e.g. health insurance coverage or co-payments). For medicines, this would require that health care need and no other potential factor determines access to and use of medicines. The empirical and policy oriented literature dealing with (in)equalities in health care revolves around three major issues: measuring the extent of the inequalities, identifying the factors that determine inequalities and addressing measures that help reduce existing inequalities.

Over the past two decades, there has been a vastly growing literature attempting to measure the existence and the extent of socioeconomic inequalities. This first stream of the literature is widely covering developing as well as developed countries (e.g. [22-24]) and has focused on access to general practitioners (GPs) or specialists [25], on access to specific treatments [26], but less on access to hospital care. Existing studies on inequalities in medicine consumption focus on single countries [27] or even regions within countries [28], on specific medicines [29] or specific groups of the population [30], while there is very little cross-country evidence on socioeconomic inequalities in medicines consumption.

The second stream of the literature goes beyond measuring (in)equalities and applies different frameworks to disentangle the factors that determine (in)equalities in access to and use of health care. Much of this work builds on Andersen's behavioural model [31], i.e. his seminal work on the predictive factors for the use of medical care. While different extensions and adaptations of the original model exist, the approach primarily differentiates between predisposing factors (including demographic factors such as age and gender, socioeconomic factors but also health beliefs or cultural norms), enabling factors (including the financial situation of the user, the means of transportation but also health care system conditions) and the need factor (differentiating between perceived need and evaluated need). Health policies (and pharmaceutical policies) largely fall into the category of contextual enabling factors. In a 2012 review of the application of Andersen's model in the 1998-2011 period [32], 328 articles have been identified, with more than half referring to the 1995 model [33]. None of the articles identified in this systematic review has dealt with the use of medicines. There are, however, studies on medicine use explicitly or implicitly referring to the ideas of the Andersen model (e.g., [34]).

Another approach to disentangling the factors that determine unequal access to health care services starts from a taxonomic definition of the 5As: availability, accessibility, accommodation, affordability and acceptability [35]. For medicines, this approach has been adapted to include availability, accessibility, acceptability and affordability, with emphasizing quality as a factor relevant in all the four dimensions [36]. In a more recent adaptation for access to health technologies including medicines, for poor populations, availability and affordability have been complemented with architecture and adoption [37]. Bigdeli et al. [38], in an attempt to grasp the complexity of barriers to accessing medicines and to more explicitly address the actors involved, differentiate between the demand side level of individuals, households and communities, health service delivery as the supply side perspective, health sector governance and the national and international context beyond the health sector.

This latter approach puts more emphasis on the health policy perspective. In addition to identifying socioeconomic inequalities in access to and use of health care and in addition to the aforementioned approaches to disentangle the factors that determine existing inequalities, the third stream of the literature on inequalities in health care use deals with the impact of policies on access to and use of medicines or on improving access to health care in general or medicines more specifically. Examples for this body of work are Gemmill et al. [39] analysing the impact of prescription medicines charges on efficiency and equity or Leopold et al. studying the impact of the economic recession on pharmaceutical consumption in eight European countries [40] and the impact of the policy policies on the use of antipsychotic medicines for Finland and Portugal [41]. In general, the more policy oriented literature is broad and often aimed at very specific health policy concerns. But often it lacks a coherent framework for analysis. For our study, we follow a WHO approach for collective action towards equitable access to essential medicines [42], differentiating between four key actions: rational selection and use 
of essential medicines, affordable prices, sustainable financing, and reliable supply systems.

With a view to the aim of this study, discussing the impact of pharmaceutical policies on (in)equalities in the use of medicines, and in combining the above cited literature, we use four key dimensions for the analysis: (1) sustainable funding, (2) affordability, (3) rational selection and use of medicines and (4) availability and accessibility. As depicted in Table 1, the first two dimensions are dealing with financing, (1) on the macro level, (2) on the micro level, the other two dimension are related to issues of delivery, (3) on the macro level, (4) on the micro level.

\section{Methods}

\section{Quantitative analysis}

We draw on cross-sectional data from the first wave of the European Health Interview Survey (EHIS), collected between 2006 and 2009 in 19 EU Member States [43]. This study focuses on CEECs. Countries in this region, due to their weaker economic situation compared to Western European countries, risk substantial socioeconomic inequalities. Eight (Bulgaria, Czech Republic, Hungary, Latvia, Poland, Romania, Slovenia, Slovakia) of the ten CEECs that were EU Member States at the time of the EHIS survey were included in our study (see Table 2 for an overview of the dataset); Estonia and Lithuania were excluded due to limited data and noninclusion in the EHIS survey, respectively. Generally, the data focussed on the non-institutionalized population, but in the Czech Republic also the institutionalized population (living in nursing homes and convents/monasteries) was included in the survey [44]. Since this, however, only concerns less than an estimated $0.5 \%$ of this country's sample population (Š Daňková 2014, pers. comm., 6 October), we hardly expect this to affect our results. Finally, the EHIS dataset covers the population above age 15 , however, we restrict our analysis to adults (aged 18 and over) as it is assumed that the development of an individual socioeconomic status may be expected from around this age onwards.

To determine the association between socioeconomic status and pharmaceutical consumption, we carried out multinomial multivariate logistic regression analyses (Stata 13.1). In these models, the probability was estimated of falling into certain categories compared to the reference group. To check the statistical significance of the calculated relative-risk ratios (RRR), z-statistics were used. Only results with $p<0.05$ were considered statistically significant and thus discussed further. McFadden's $\mathrm{R}^{2}$ is reported as measure of model fit.

A detailed description of the variables included in the regression analysis can be found in Table 3. The dependent variable is based on the information on the consumption of non-prescribed medicines (only), consumption of prescribed medicine (only) and consumption of both types of medicines versus no medicine use. For an unbiased gender comparison, use of femalespecific medicines (contraceptive pills; hormones for menopause; based on an additional survey question) was excluded from the analysis. As independent variables of interest, three socioeconomic indicators were included [45]. First, employment status was grouped into employed (reference group), retired, unemployed or disabled and in training or at home. Second, the highest level of education completed was measured based on the International Standard Classification of Education (ISCED) 1997 and distinguishes between ISCED $\leq 2$, ISCED 3-4 and ISCED 5-6. Third, the income level was based on the range of the monthly net household income against the values of the national deciles' limits and categorized into quintiles (reference group: first quintile). To control for demographic characteristics, we included age and sex, with the youngest and males as reference groups. Finally, since a socioeconomic gradient in health disadvantaging the poor is also well-established

Table 1 Pharmaceutical policies and equitable access to medicines: a framework for analysis

\begin{tabular}{|c|c|c|}
\hline & Macro level & Micro level \\
\hline \multirow[t]{3}{*}{ FINANCING } & Sustainable funding & Affordability \\
\hline & $\begin{array}{l}\text { Addressing financial issues on macro levels: the availability of funding } \\
\text { for health care in general and the level of pharmaceutical spending } \\
\text { more specifically }\end{array}$ & $\begin{array}{l}\text { Addressing financial issues on micro levels: who pays and how much, } \\
\text { thus the role of public and private payments for pharmaceuticals }\end{array}$ \\
\hline & $\begin{array}{l}\text { Categories of indicators: type of health care system, total health } \\
\text { expenditure, pharmaceutical expenditure }\end{array}$ & $\begin{array}{l}\text { Categories of indicators: private health expenditure, private } \\
\text { pharmaceutical expenditure, co-payments, informal payments, } \\
\text { medicine prices, VAT on medicines, policies addressing the poor }\end{array}$ \\
\hline \multirow[t]{3}{*}{ DELIVERY } & Rational selection and use & Availability and accessibility \\
\hline & $\begin{array}{l}\text { Addressing delivery on macro levels: which medicines, at least } \\
\text { potentially, are made available, rational prescribing, dispensing and } \\
\text { use of medicines in the health care system }\end{array}$ & $\begin{array}{l}\text { Addressing delivery on micro levels: the issue of supply meeting } \\
\text { demand in terms of volume and reachability given distances and } \\
\text { travel resources }\end{array}$ \\
\hline & $\begin{array}{l}\text { Categories of indicators: INN prescribing, generic market, reference } \\
\text { price system, prescription monitoring, treatment guidelines }\end{array}$ & $\begin{array}{l}\text { Categories of indicators: number of medicines, pharmacy density, } \\
\text { OTC sale }\end{array}$ \\
\hline
\end{tabular}


Table 2 Data sources

\begin{tabular}{|c|c|c|c|c|c|c|c|c|}
\hline & BG & $C Z$ & $\mathrm{HU}$ & LV & $\mathrm{PL}$ & $\mathrm{RO}$ & $\mathrm{SI}$ & SK \\
\hline Fieldwork & $\begin{array}{l}10 / 2008- \\
11 / 2008\end{array}$ & $\begin{array}{l}06 / 2008- \\
10 / 2008\end{array}$ & $\begin{array}{l}09 / 2009- \\
10 / 2009\end{array}$ & $\begin{array}{l}09 / 2008- \\
12 / 2008\end{array}$ & $\begin{array}{l}10 / 2009- \\
12 / 2009\end{array}$ & $\begin{array}{l}05 / 2008- \\
06 / 2008\end{array}$ & $\begin{array}{l}\text { 10/2007- } \\
11 / 2007\end{array}$ & $\begin{array}{l}09 / 2009- \\
10 / 2009\end{array}$ \\
\hline Response rate in \% & 74 & 56 & 81 & 72 & 72 & 89 & 68 & 66 \\
\hline Sample size (age 15+) & 5,661 & 1,995 & 5,051 & 6,458 & 35,100 & 18,172 & 2,188 & 4,972 \\
\hline
\end{tabular}

Note: BG Bulgaria, CZ Czech Republic, HU Hungary, LV Latvia, PL Poland, RO Romania, SI Slovenia, SK Slovakia Source: Eurostat [44]

in CEE regions [46], we introduced dummy variables for chronic conditions (no chronic conditions as reference group) and self-assessed health (good as reference group).

An overview of the descriptive information for the individual countries is given in Table 4 .

\section{Pharmaceutical policy analysis}

The analysis of pharmaceutical policies as potential codeterminant of inequalities in medicine use builds on an analytical framework based on the WHO approach for collective action [42] (see Addressing inequalities in medicine use and Table 1). We identified four key

Table 3 Variable definitions

\begin{tabular}{|c|c|c|}
\hline Variable & Survey question & Subcategories (as used in the analysis) and reference group \\
\hline \multirow[t]{2}{*}{ Medicine use } & $\begin{array}{l}\text { During the past two weeks, have you used any medicines } \\
\text { (including dietary supplements such as herbal medicines } \\
\text { or vitamins) that were prescribed or recommended for } \\
\text { you by a doctor? }\end{array}$ & $\begin{array}{l}\text { - None; reference group } \\
\text { - Non-prescribed } \\
\text { - Prescribed } \\
\text { - Both }\end{array}$ \\
\hline & $\begin{array}{l}\text { During the past two weeks, have you used any medicines } \\
\text { or dietary supplement or herbal medicines or vitamins } \\
\text { not prescribed or recommended by a doctor? }\end{array}$ & \\
\hline Employment status & How would you define your current labour status? & $\begin{array}{l}\text { - Employed (working for pay or profit); reference group } \\
\text { - Retired (in retirement or early retirement or has given up business) } \\
\text { - Unemployed or disabled (unemployed; permanently disabled) } \\
\text { - In training or at home (pupil, student, further training, unpaid } \\
\text { work experience) }\end{array}$ \\
\hline Highest education & $\begin{array}{l}\text { What is the highest education leaving certificate, diploma } \\
\text { or education degree you have obtained? Please include } \\
\text { any vocation training. }\end{array}$ & $\begin{array}{l}\text { - ISCED } \leq 2 \text { (no formal education or below ISCED 1; primary } \\
\text { education; lower secondary education); reference group } \\
\text { - ISCED 3-4 (upper secondary education; post-secondary but } \\
\text { non-tertiary education) } \\
\text { - ISCED 5-6 (first stage of tertiary education; second stage of } \\
\text { tertiary education) }\end{array}$ \\
\hline Income quintile & $\begin{array}{l}\text { Perhaps you can provide the appropriate range [instead } \\
\text { of the household's total net income per month]. Would } \\
\text { you (please look at this card and) tell me which group } \\
\text { represents your household's total net monthly income } \\
\text { from all these sources after deductions for income tax, } \\
\text { National Insurance etc. Is it ... }\end{array}$ & $\begin{array}{l}\text { - First quintile; reference group } \\
\text { - Second quintile } \\
\text { - Third quintile } \\
\text { - Fourth and fifth quintile }\end{array}$ \\
\hline Age & Age of the person at the moment of the interview & $\begin{array}{l}\cdot 18-29 \text { years } \\
\cdot 30-39 \\
\cdot 40-49 \\
\cdot 50-59 \\
\cdot 60-69 \\
\cdot 70+\end{array}$ \\
\hline Gender & Sex & $\begin{array}{l}\text { - Male; reference group } \\
\text { - Female }\end{array}$ \\
\hline Chronic conditions & $\begin{array}{l}\text { Do you have any longstanding illness or [longstanding] } \\
\text { health problem? [By longstanding, I mean illnesses or } \\
\text { health problems which have lasted, or are expected to } \\
\text { last, for } 6 \text { months or more.] }\end{array}$ & $\begin{array}{l}\text { - No; reference group } \\
\text { - Yes }\end{array}$ \\
\hline Self-assessed health & How is your health in general? Is it ... & $\begin{array}{l}\text { - Good (very good, good); reference group } \\
\text { - Poor (very bad, bad, fair) }\end{array}$ \\
\hline
\end{tabular}

Note: ${ }^{a}$ As pointed out by an anonymous reviewers, it can be argued that unemployed and permanently disabled people differ in terms of health and medicine use and should thus be analysed separately. However, as both groups individually make for a small proportion of the sample and thus only very few observations would be left for the subgroup analyses (in the most extreme case 0 observations and in the majority of cases, less than 20 observations, which, for Eurostat confidentially reasons would need to be left blank), it was decided to analyse them as one subgroup.

Source: Data provided by Eurostat [80]; presentation by the authors 
Table 4 Descriptive information

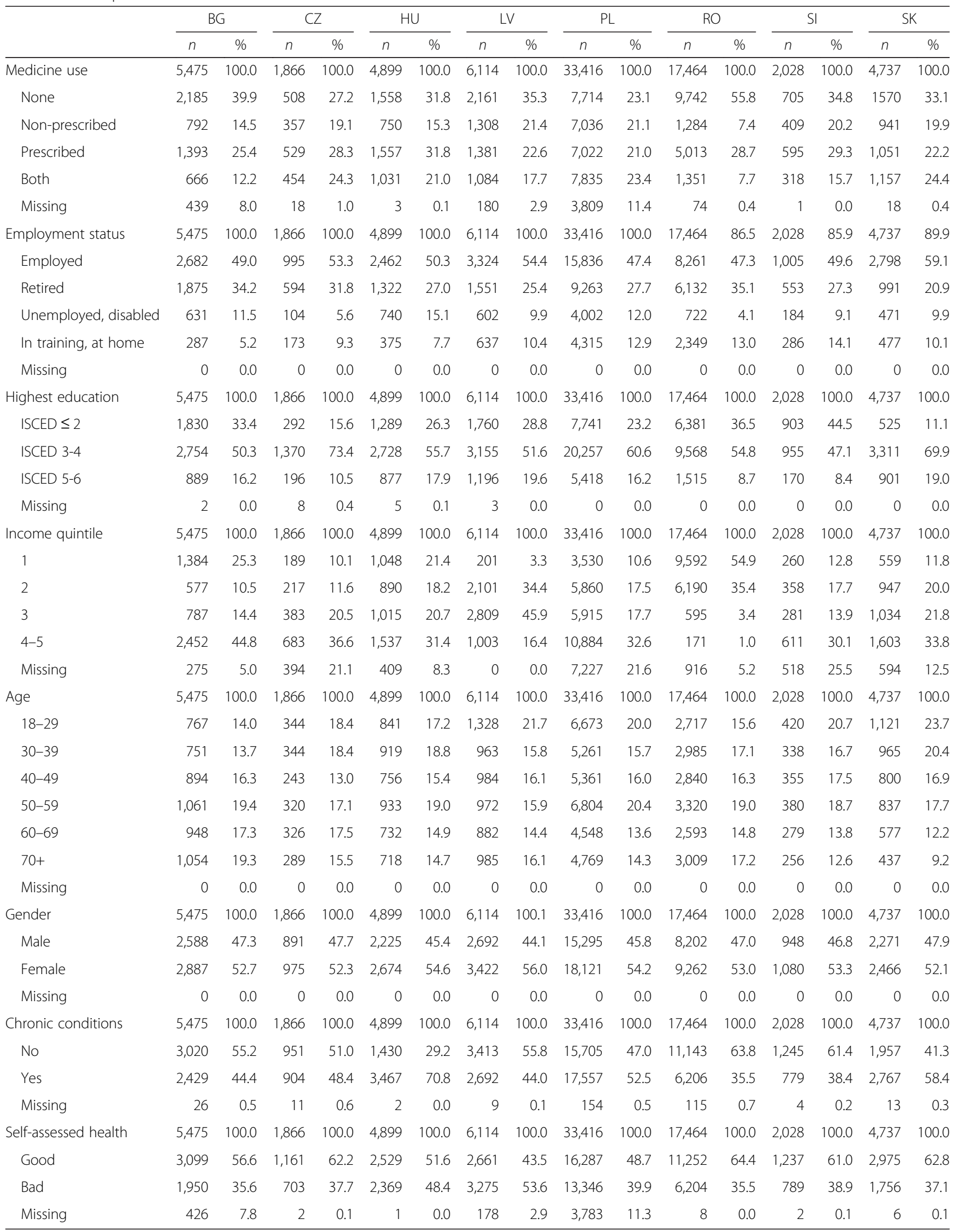


dimensions for the analysis, (1) sustainable funding, (2) affordability, (3) rational selection and use of medicines and (4) availability and accessibility. For each of the four dimensions, we developed a set of indicators (see Tables 1 and 5).

To fill these indicators with country specific information, we drew on several data sources: Background information and data for the policy analysis were taken from the literature, predominantly grey literature. Search terms included 'medicines', 'pharmaceuticals', 'equity', 'access' and the name of the country. We focussed on the period around the EHIS survey, and three years before, and also literature with overall relevant information, e.g. related to the transition process, was included. Country reports about national pharmaceutical systems were a key source of information, in particular the PPRI (Pharmaceutical Pricing and Reimbursement Information) Pharma Profiles (available for five of the eight CEECs), the Health Systems in Transition reports by the European Observatory on Health Systems and Policies as well as country reports produced by the Organisation for Economic Co-operation and Development (OECD) and by the Austrian Public Health Institute (references listed below Table 5 and below the additional table [see Additional file 1]). Since some of the reports did not refer to the exact years of the survey, unpublished information from the PPRI network was used as supplementary source $[47,48]$. Health and pharmaceutical expenditure data were retrieved from the Eurostat database [49].

Based on the information and data collected for the countries, we produced eight brief country posters [see Additional file 1]) and an overview table (Table 5). Following methods of policy analysis research [50], we used the country specific information and data to understand whether the identified socioeconomic (in)equalities in medicine use were impacted by the existing implementation degree of pharmaceutical policies. In the analysis, we interpreted 'prescribed medicines' as medicines funded, at least partially, by state (independently from their prescription status: both prescription-only and non-prescription medicines), whereas 'non-prescribed medicines' were considered as non-funded self-medication.

\section{Results}

As can be seen from the descriptive information for the individual countries (Table 4), the proportion of people reporting to take no medicine at all ranged between $23.1 \%$ (Poland) and $39.9 \%$ (Bulgaria) in all countries except for Romania, in which 55.8 \% reported no medicine consumption. Romania also holds a special position regarding non-prescribed medicine use (7.4\%), which lied between $14.5 \%$ (Bulgaria) and 21.4 \% (Latvia) in the remaining countries. Prescribed medicines (only) were taken by around $21.0 \%$ (Poland) and $31.8 \%$ (Hungary) of the surveyed populations.

\section{Socioeconomic (in)equalities in medicine use}

Overall, in the regression analyses we find that whenever there is a socioeconomic gradient in medicine consumption to be observed in a country, it will in virtually every case favour the well-off, as shown in Figs. 1 and 2, respectively. The full results including all variables of the countryspecific multinomial logistic regression analyses are presented in an additional table [see Additional file 2].

For non-prescribed medicine use (versus no medicine use), individuals with higher education and/or income had a higher chance of taking such medicines in seven of the eight CEECs: In Hungary, for instance, individuals in the highest education group were estimated to be four times more likely to take non-prescribed medicines $(\mathrm{RRR}=4.32,95 \% \mathrm{CI}=2.98-6.27)$ while the relative risk for people in high income households increases by a factor of 1.66 (95\% CI $=1.20-2.31$ ), respectively, given the other variables in the model are held constant. In Poland, on the other hand, the observed gradient was comparably less pronounced (highest education: $\mathrm{RRR}=$ $1.79,95 \% \mathrm{CI}=1.55-2.07$; highest income: $\mathrm{RRR}=1.38$, $95 \% \mathrm{CI}=1.20-1.58)$. Only in Bulgaria, neither education nor income played any role for non-prescribed medicine use, but the unemployed and disabled were attributed a lower consumption likelihood.

For prescribed medicines, in contrast, a statistically significant socioeconomic gradient could be identified in three economies only, i.e. Latvia, Poland, Romania: The increased likelihood of the highest education groups in these countries (Latvia: $R R R=2.09,95 \% \mathrm{CI}=1.59-2.73$; Poland: $\mathrm{RRR}=1.92,95 \% \mathrm{CI}=1.62-2.27$; Romania: $\mathrm{RRR}=$ $1.73,95 \% \mathrm{CI}=1.19-2.54)$ is similar in magnitude, whereas in terms of the highest income groups, Latvia showed the most pronounced effect with an RRR close to $2(\mathrm{RRR}=1.99,95 \% \mathrm{CI}=1.17-3.37)$.

Regarding the influence of demographic characteristics on medicine use [see Additional file 2], females were more likely to take (any) medicines in general, whereas advanced age was particularly relevant for prescribed pharmaceutical consumption, which is consistent with the literature [51]. Such prescribed medicine use was also highly determined by health characteristics, especially by longstanding illnesses.

\section{Pharmaceutical policies}

Details on the pharmaceutical policies in the CEECs are provided in Table 5 and an additional table [see Additional file 1]. Key features are as follows: Health and pharmaceutical expenditure, primarily funded by social health insurance contributions, was low compared to the Western European countries, and the 
Table 5 Pharmaceutical policy framework - Indicators for equitable access to essential medicines

\begin{tabular}{|c|c|c|c|c|c|c|c|c|}
\hline Indicator & $B G$ & $\mathrm{CZ}$ & $\mathrm{HU}$ & LV & $\mathrm{PL}$ & $\mathrm{RO}$ & $\mathrm{SI}$ & SK \\
\hline Reference year & 2008 & 2008 & 2009 & 2008 & 2009 & 2008 & 2007 & 2009 \\
\hline \multicolumn{9}{|l|}{ Sustainable funding } \\
\hline HC system & $\mathrm{SHI}$ & $\mathrm{SHI}$ & $\mathrm{SHI}$ & $\mathrm{SHI}$ & $\mathrm{SHI}$ & $\mathrm{SHI}$ & $\mathrm{SHI}$ & $\mathrm{SHI}$ \\
\hline TPE in \% of THE & $33.4 \%$ (0.0 pp) & $20.4 \%(-4.4$ pp) & $32.5 \%$ (+1.5 pp) & $19.4 \%(-2.6$ pp) & $22.9 \%(-4.3 \mathrm{pp})$ & $25.0 \%(-3.2 \mathrm{pp})$ & $19.6 \%$ (-1.1 pp) & $26.6 \%(-3.2 \mathrm{pp})$ \\
\hline $\begin{array}{l}\text { TPE share } \\
\text { (CEE-10 comparison) }\end{array}$ & $+9.0 \mathrm{pp}$ & $-4.0 \mathrm{pp}$ & $+6.7 \mathrm{pp}$ & $-5.0 \mathrm{pp}$ & $-1.5 \mathrm{pp}$ & $+0.6 \mathrm{pp}$ & $-6.0 \mathrm{pp}$ & $+3.2 \mathrm{pp}$ \\
\hline TPE per capita & $€ 109.9$ (+50.3\%) & $€ 205.6(+17.1 \%)$ & $€ 229.4$ (+0.8 \%) & $€ 134.3$ (+66.6 \%) & $€ 134.5$ (+11.7\%) & $€ 92.2(+59.1 \%)$ & $€ 264.0(+12.0 \%)$ & $€ 283.5$ (+56.6 \%) \\
\hline $\begin{array}{l}\text { TPE/capita } \\
\text { (CEE-10 comparison) }\end{array}$ & $-39.1 \%$ & $+14.0 \%$ & $+35.3 \%$ & $-25.6 \%$ & $-16.5 \%$ & $-48.9 \%$ & $+56.9 \%$ & $+47.0 \%$ \\
\hline \multicolumn{9}{|l|}{ Affordability } \\
\hline Private HE/THE & $41.8 \%$ (+6.5 \%) & $17.5 \%(+37.5 \%)$ & $34.3 \%$ (+13.5 \%) & $37.4 \%(-12.7 \%)$ & $28.2 \%(-6.0 \%)$ & $18.0 \%$ (-6.2 \%) & $28.1 \%(+4.6 \%)$ & $34.3 \%(+8.3 \%)$ \\
\hline $\begin{array}{l}\text { Private HE/THE } \\
\text { (CEE-10 compar.) }\end{array}$ & $+13.6 \mathrm{pp}$ & $-10.8 \mathrm{pp}$ & $+4.7 \mathrm{pp}$ & $+9.2 \mathrm{pp}$ & $-0.1 \mathrm{pp}$ & $-10.3 \mathrm{pp}$ & $-2.2 \mathrm{pp}$ & $+4.0 \mathrm{pp}$ \\
\hline Private PE/TPE & $81.7 \%(+4.8 \%)$ & $38.4 \%(+56.9 \%)$ & $51.6 \%$ (37.7 \%) & $62.2 \%(-9.4 \%)$ & $61.4 \%$ (0 \%) & $55.0 \%(+4.8 \%)$ & $40.1 \%(+2.9 \%)$ & $30.2 \%(+11.3 \%)$ \\
\hline $\begin{array}{l}\text { Private PE/TPE } \\
\text { (CEE-10 comp.) }\end{array}$ & $+27.8 \mathrm{pp}$ & $-15.5 \mathrm{pp}$ & $-2.9 \mathrm{pp}$ & $+8.3 \mathrm{pp}$ & $+7.8 \mathrm{pp}$ & $+1.2 \mathrm{pp}$ & $-13.7 \mathrm{pp}$ & $-25.2 \mathrm{pp}$ \\
\hline Informal pays & Yes, extensive & Yes & Yes & Yes, extensive & Yes & Yes, large scale & No & Yes \\
\hline Medicine prices & n.a. & $€ 5.09(-71.4 \%)$ & $€ 6.91(-61.2 \%)$ & $€ 4.23(-76.2 \%)$ & $€ 4.54(-74.5 \%)$ & n.a. & $€ 12.34(-30.8 \%)$ & n.a. \\
\hline \multirow[t]{3}{*}{ Co-pays (out-patient) } & No PF & PF & PF & No PF & PF for some indications & No PF & No PF & PF \\
\hline & $\begin{array}{l}\%: 0 \%,>25 \\
\%,>50 \%\end{array}$ & No fixed $\mathrm{R}$ rates & $\begin{array}{l}\%: 0 \%, 10 \%, 30 \% \\
25 \%, 45 \%, 75 \%\end{array}$ & $\begin{array}{l}\%: 0 \%, 10 \%, 25 \%, \\
50 \%, 25 \%\end{array}$ & $\%: 0$ \%, $30 \%, 50 \%$ & $\%: 0 \%, 10 \%, 50 \%$ & $\begin{array}{l}\%: 0 \%, 25 \%, \\
75 \%\end{array}$ & \%: no fixed $\mathrm{R}$ rates \\
\hline & No D & No $D$ & No $D$ & No D & No D & No $D$ & No $D$ & No D \\
\hline Changes in co-pays & No & Yes & Yes, increase & $\begin{array}{l}\text { No, but planned ( } 90 \% \\
\text { R rate to be abolished) }\end{array}$ & $\begin{array}{l}\text { No since mid- } \\
\text { 1990-ties }\end{array}$ & No & No & $\begin{array}{l}\text { Yes, decrease in PF } \\
\text { in 10/2006 }\end{array}$ \\
\hline Co-pay exempt. & None & None & Yes & Yes & Yes & Yes, see comment & Yes & Yes \\
\hline De-listings & No, see comment & Not known & Yes, see comment & See comment & Yes & See comment & No & No major delisting \\
\hline Co-pays (in-patient) & No co-payment & No co-payment & No co-payment & No co-payment & No co-payment & No co-payment & No co-payment & No co-payment \\
\hline VAT on medicines & $20 \%(20 \%)$ & $9 \%(19 \%)$ & $5 \%(20 \%)$ & $\begin{array}{l}5 \%(18 \%) \text {, planned } \\
\text { increase from 1/2009 }\end{array}$ & $7 \%(22)$ & $9 \%(19 \%)$ & $8.5 \%$ (20 \%) & $10 \%(19 \%)$ \\
\hline OTC market & $22 \%$ & $26.8 \%$ & $15.8 \%$ & n.a. & $25.8 \%$ & $22.4 \%$ & $6.7 \%$ & $25.8 \%$ \\
\hline \multicolumn{9}{|c|}{ Availability and accessibility } \\
\hline \multirow[t]{4}{*}{ No. of medicines } & $5,830^{2006}$ & $7,880^{2006}$ & $5,525^{2006}$ & n.a. & $\left(8,089^{2005}\right)$ & $6,711^{2007}$ & $2,791^{2006}$ & 19,693 November 2006 \\
\hline & $4,481^{2006}$ & $4,130^{2006}$ & $3,144^{2006}$ & $5,714^{2007}$ & $4,275^{2006}$ & $\approx 4,000^{2007}$ & n.a. & $19,320^{\text {November }} 2006$ \\
\hline & 1,598 & $6,988^{2006}$ & $2,886^{2006}$ & $2,337^{2007}$ & $2,749^{2006}$ & $5,791^{2007}$ & $2,660^{2006}$ & $17,804^{\text {November }} 2006$ \\
\hline & See comment & & See comment & See comment & See comment & See comment & See comment & See comment \\
\hline
\end{tabular}


Table 5 Pharmaceutical policy framework - Indicators for equitable access to essential medicines (Continued)

\begin{tabular}{|c|c|c|c|c|c|c|c|c|}
\hline Pharmacies & $4,299 / 1,795^{2006}$ & $2,520 / 4,096^{2007}$ & $\approx 2,500 / \approx 4,000^{2010}$ & $899 / 2,209^{2007}$ & $10,632 / 3,585^{2007}$ & $5,660 / 3,733^{2007}$ & $271 / 7,384^{2005}$ & $1,523 / 3,528^{\text {Oct. } 2006}$ \\
\hline $\begin{array}{l}\text { OTC sale outside } \\
\text { pharmacies permitted }\end{array}$ & Yes & Yes & Yes & No & No & $\begin{array}{l}\text { Yes, but pharmacist } \\
\text { must be present }\end{array}$ & Yes & No \\
\hline \multicolumn{9}{|c|}{ Rational selection and use of medicines } \\
\hline INN prescribing & Yes, indicative & Yes, indicative & Yes, indicative & Yes, indicative & Yes, indicative & Yes, indicative & Yes, indicative & Yes, indicative \\
\hline Generic substitution & No, not allowed & Yes, indicative & Yes, indicative & Yes, obligatory & Yes, indicative & Yes, indicative & Yes, indicative & Yes, obligatory \\
\hline Ref. price syst. & Yes, ATC 5 & Yes, ATC $4+5$ & Yes, ATC $4+5$ & Yes, ATC 3,4+5 & Yes, ATC 3,4+5 & Yes, ATC 5 & Yes, ATC 4 & Yes, ATC $4+5$ \\
\hline Generic market & See comment & $55 \% / 35 \% 2005$ & $42 \% / 26 \%$ & No data & No data & $\approx 70 \% / \approx 40 \%{ }^{\mathrm{e}}$ & $70 \% / 38 \% 2005$ & $65 \% / 48 \%{ }^{2005}$ \\
\hline $\begin{array}{l}\text { Prescription } \\
\text { monitoring }\end{array}$ & Yes, but limited & Yes & $\begin{array}{l}\text { Yes, but limitations } \\
\text { in enforcement }\end{array}$ & Yes & $\begin{array}{l}\text { Yes, but limitations } \\
\text { in enforcement }\end{array}$ & $\begin{array}{l}\text { Yes, but limitations } \\
\text { in enforcement }\end{array}$ & Yes & Yes \\
\hline
\end{tabular}

Indicators:

Reference year: data in this table refer to the year of the household survey unless indicated differently

HC system: indicates the type of health care system: Semaskho system, social health insurance (SHI) or National Health Service (NHS)

TPE in \% of THE: Total pharmaceutical expenditure (TPE) in \% of total health expenditure (THE) in the year of the survey; in brackets: change in the share of TPE in \% of THE in percentage points compared to

3 years earlier

TPE share (CEE-10 comparison): Difference of the share of TPE in \% of THE in the surveyed country in 2008 compared to CEE-10 average (Bulgaria, Czech Republic, Estonia, Latvia, Lithuania, Hungary, Poland, Romania, Slovenia, Slovakia) in 2008, expressed in percentage points

TPE per capita: Total pharmaceutical expenditure (TPE) per capita in the year of the survey, in Euro; in brackets: change in TPE per capita compared to 3 years earlier, expressed in per cent)

TPE/capita (CEE-10 comparison): Difference of the TPE per capita in the surveyed country in 2008 compared to CEE-10 average in 2008, expressed in per cent

Private HE/THE: Private health expenditure (HE) in \% of total health expenditure (THE) in the year of the survey (unless BG - 2007 data); in brackets: change in the share of private HE in \% of THE in per cent compared to 3 years earlier

Private HE/THE (CEE-10 compar.): Difference of the share of private HE in \% of THE in the surveyed country in 2008 compared to CEE-10 average in 2008 (unless BG - 2007 data), expressed in percentage points Private PE/TPE: Private pharmaceutical expenditure (PE) in \% of total pharmaceutical expenditure (TPE) in the year of the survey; in brackets: change in the share of private PE in \% of TPE in per cent compared to 3 years earlier

Private PE/TPE (CEE-10 comp.): Difference of the share of private PE in \% of TPE in the surveyed country in 2008 compared to CEE-10 average in 2008, expressed in percentage points Informal pays: Indications of informal payments in health care

Medicine prices: Average pharmacy retail price in $€$ per pack in the total out-patient market in 2006; differences in \% to average of EU-15

Co-pays (out-patient): Co-payments for medicines in the out-patient sector: $\mathrm{PF}=$ prescription fee, $\%=$ percentage co-payment rates (for reimbursable medicines different co-payment rates in per cent of the price of product apply, usually linked to the severity of the disease and therapeutic benefit of the medicine), $\mathrm{D}=$ deductible (upfront initial out-of-pocket payment up to a fixed amount for a service or over a defined period of time; then the rest of the cost is covered by a public party payer). Percentage co-payments due to the reference price system (see below indicator 'Ref. pricing syst.') are not considered.

Changes in co-pays: Changes in co-payments in the years before the survey

Co-pay exempt.: Mechanisms for vulnerable groups (e.g. exemptions, reductions) from co-payments in the out-patient sector

De-listings: Exclusion of medicines from reimbursement in the years before the survey

Co-pays (in-patient): Co-payments for medicines in the in-patient sector

VAT on medicines: Value-added tax (VAT) rate on medicines; in bracket: standard VAT rate

OTC market: Relevance of the Over-the-Counter (OTC) market expressed by the share of sales in total non-prescription market as per cent of total pharmaceutical market sales in the years of the EHIS survey (at consumer price level, unless indicated differently)

No. of medicines: Number of medicines authorized, medicines on the market, and prescription-only medicines. Counted incl. different pharmaceutical forms and dosages, excl. different pack sizes unless indicated differently

Pharmacies: Number of community pharmacies, and inhabitants per pharmacy served

OTC sale outside pharmacies permitted: Information as to whether the sale of Over-the-Counter (OTC) medicines was permitted outside pharmacies, or not

INN prescribing: Information as to whether prescribing by International Non-Proprietary Name (INN) was permitted, and if yes, whether the policy was voluntary (indicative) or mandatory for the prescriber

Generic substitution: Information as to whether the practice of substituting a medicine, whether marketed under a trade name or generic name (branded or unbranded generic), with a less expensive medicine (e.g. branded or unbranded generic), often containing the same active ingredient, was permitted, and if yes, whether the policy was voluntary (indicative) or mandatory for the pharmacist

Ref. price syst.: Information as to whether a reference price system was in place, i.e. a reimbursement policy, in which identical or similar medicines are clustered - the public payer reimburses a defined maximum amount (reference price) for all medicines of the cluster, and patients have to co-pay the remainder up to the pharmacy retail price gross), and its clustering: ATC-5: clustering of same active ingredients or groups of active ingredients, ATC-4: clustering of medicines of the same therapeutic group, clustering of medicines of the same pharmacological subgroup

Generic market: Generic market share (in value and in volume) in the out-patient sector 
Prescription monitoring: Information as to whether prescription monitoring was performed

Abbreviations: ATC Anatomical Therapeutic Chemical classification system, $D$ deductible, HE health expenditure, OTC Over-the-Counter medicines, $p p$ percentage points, $P E$ pharmaceutical expenditure, $P F$ prescription fee, $R$ reimbursement, THE total health expenditure, TPE total pharmaceutical expenditure, VAT value-added tax

Nee, $R$ res:

BG:

Private HE / THE and Private HE / THE (CEE-10 compar.): no data for private health expenditure in 2008 available; 2007 data used instead: change indicated for the years $2004-2007$

Changes in co-pays: Increase of percentage co-payments for some medicines, treating Parkinson, osteoporosis, Glaucoma, etc. took place after the EHIS survey, in 2010

De-listings: No de-listings reported but constant increase of medicines included in the positive list during 2007

No. of medicines: Different data sources and counting methods for medicines authorized and on the market compared to prescription-only medicines. The latter were counted per brand name, excl. different pharmaceutical forms dosages and pack sizes. Counted according to that method, the number of the medicines on the market were 4,299, thus resulting in a share of prescription-only medicines of the medicines on the market of around $37 \%$. Pharmacies: High regional disparities in the density of pharmacies, concentration in larger cities

Generic market: No data on generic market shares available. $74 \%$ of the medicines on the market are generics.

CZ:

Co-pays (out-patient): Percentage co-payment rates result from application of the reference price system

Changes in co-pays: In 2008 (year of the survey), a prescription fee was introduced, as well as further co-payments in health care (not medicines related) such as a co-payment for visit to a doctor

Pharmacies: High regional disparities in the density of pharmacies, concentration in larger cities

$\mathrm{HU}:$

Co-pays (out-patient): Percentage co-payment rates of 0,10 and $30 \%$ for out-patient medicines for specific indications, and of 25,45 and $75 \%$ for all other reimbursable medicines in the out-patient sector

Co-pay exempt.: Exemptions from co-payment for socially disadvantaged persons. $100 \%$ reimbursement for patients with long-term illness, however, the prescription fee had also to be paid by them

De-listings: A few de-listings, and changes in reimbursement categories (pharmaceutical groups were granted a lower percentage reimbursement rate) at large scale since 2006/2007

No. of medicines: Counted per brand name, excl. different pharmaceutical forms, dosages and pack sizes

Pharmacies: In addition to pharmacies, around 370 doctors are also allowed to dispense prescription-only medicines

Prescription monitoring: Limitations particularly related to off-patent medicines: guidelines for cost-effective prescribing are frequently not followed, no audit or feed-back of the social health insurance on generic prescribing by doctors

LV:

De-listings: De-listings were not explicitly reported but took place most probably: since 2005 major changes in the reimbursement list were reported, the principle of a limited number of medicines in the positive list was in place, and regular reimbursement reviews were performed. Medicines were included in the positive list for a period of 2 years, then the marketing authorization holder had to apply for re-inclusion. No. of medicines: Number of medicines authorized not included since medicines are only counted per trade name

Pharmacies: Including 100 branch pharmacies, availability of pharmacies varied between towns and rural areas

PL:

OTC market: At manufacturer price level; refers to self-medication market

No. of medicines: Data on number of prescription-only medicines includes hospital-only medicines. In 2009, 3,380 medicines (counted including different pharmaceutical forms, dosages and pack sizes) were on the reimbursement list. Data on authorized medicines have to be interpreted with caution due to a different counting method: counted including different dosages, pharmaceutical forms and pack sizes.

Pharmacies: High regional disparities in the density of pharmacies, concentration in larger cities

RO:

Co-pay exempt.: Exemptions from co-payments are made for children, students and pregnant women as well as war veterans and disabled people on low income

De-listings: Quarterly updates of the reimbursement lists; no confirmed information of major de-listings (however number of medicines on the reimbursement list is, in general, rather low)

No. of medicines: 1,247 of the 5,791 prescription-only medicines were hospital-only medicines

Pharmacies: High regional disparities in the density of pharmacies, concentration in larger cities

Generic market: Estimate for the year 2007

Co-pays (out-patient): Co-payments covered by voluntary insurance that around $90 \%$ of the population concluded

Co-pay exempt.: Exemptions from co-payments for medicines for prevention, for defined social groups (such as people under 18 years) or for the treatment of specific diseases (e.g. HIV/AIDS, diabetes)

De-listings: No major wave of de-listings reported; on the contrary, some new medicines could be included in the positive lists following changes in medicine prices due to change in pricing methodology

OTC market: At wholesale price level, refers to self-medication market

No. of medicines: Counted including different dosages, pharmaceutical forms and pack sizes

Pharmacies: Some OTC medicines were 'pharmacy-only', whereas others were permitted to be sold in 'specialised stores' outside pharmacies

SK:

No. of medicines: Counted including different pharmaceutical forms, dosages and pack sizes; homeopathic medicines excluded

Sources: Indicator 2: [7, 10, 81-89]; Indicators 3-10: [49]; Indicator 11: [14-16, 63, 83, 86, 88-100]; Indicator 12: [68]; Indicators 13-16, 18, 20, 22-24, 26, 27: [9, 63, 101-111]; Indicator 17: [112-117]; Indicator 19: [53-55]; Indicator 21: pharmacy data and information on disparities: [7, 9, 63, 82, 84, 86, 102, 103, 105, 111, 118, 119], population data: [49]; Indicator 25: RO: [12, 63] 


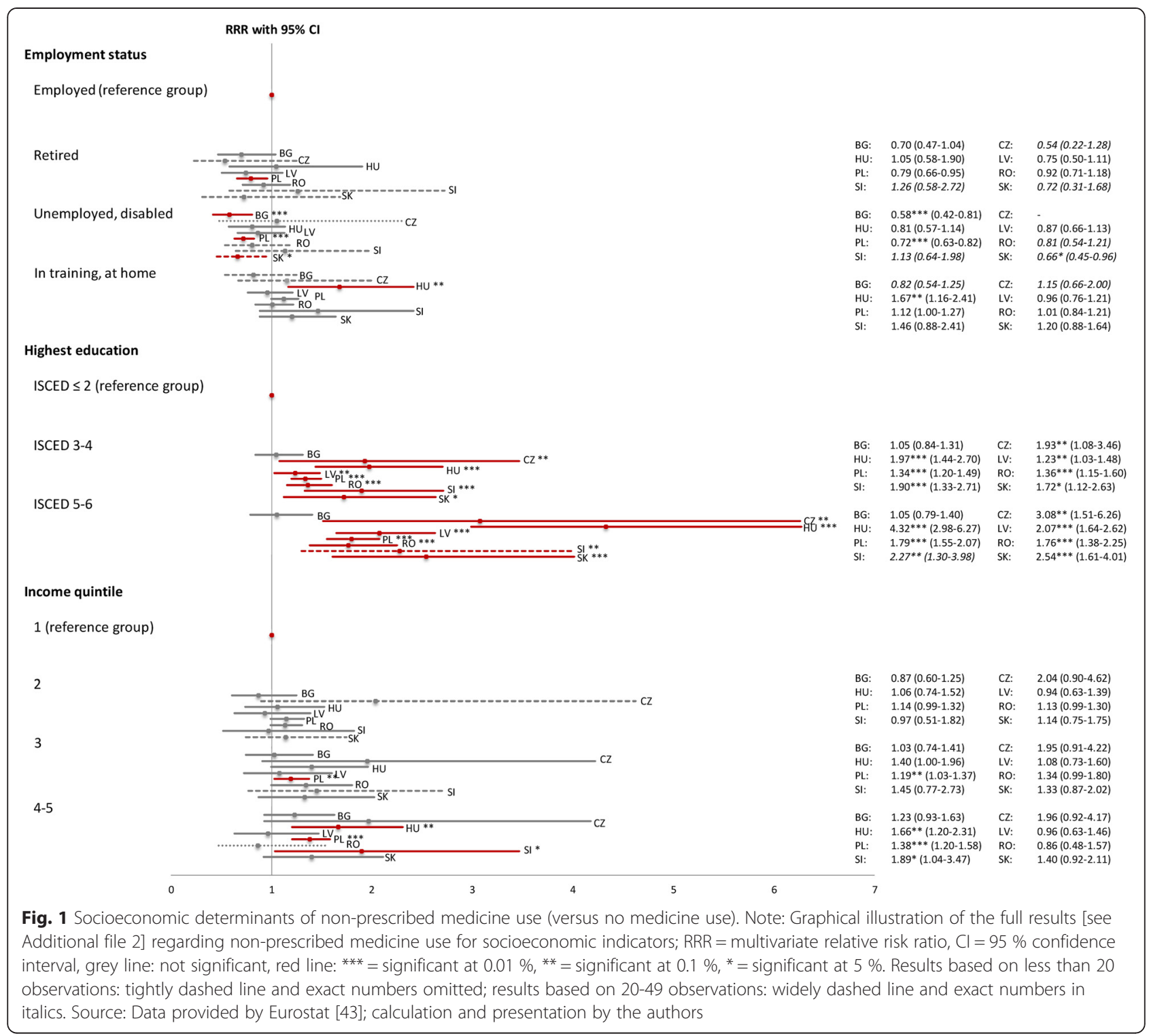

share of health expenditure spent on medicines was rather high. In 2008, the EU-15 (i.e. 15 countries from Western, Northern and Southern Europe that joined the EU before 2004), spent an average of $€ 424$ on medicines, corresponding to around $15.6 \%$ of total health expenditure, whereas average figures equalled to $€ 180$ and $24.4 \%$ in the CEE-10 (the eight surveyed countries plus Estonia and Lithuania) [49, 52]. Within the eight surveyed CEECs, major discrepancies existed both in terms of the share of health expenditure spent on medicines and per capita pharmaceutical expenditure. Pharmaceutical expenditure was particularly low in Romania and Bulgaria, and also in Latvia and Poland. High increases in pharmaceutical expenditure were observed in Latvia (67\% during the three years before the survey), Romania (59 \%) and Slovakia (57\%).

Private funding of health care, particularly of medicines (on average $54 \%$ in the CEE-10), was high compared to the EU-15 with $38 \%[49,52]$, and there was considerable variation between the surveyed CEECs: Bulgaria had the highest share of private pharmaceutical spending (82\%), followed by Latvia (62\%) and Poland (61 \%). Apart from Latvia and Poland, the share of private pharmaceutical expenditure had grown in the three years before the EHIS survey, particularly in the Czech Republic (57 \%) and Hungary (38 \%). Private pharmaceutical expenditure resulted from full out-of-pocket payments in the case of self-medication (non-prescribed, non-reimbursable medicines) and from co-payments of 


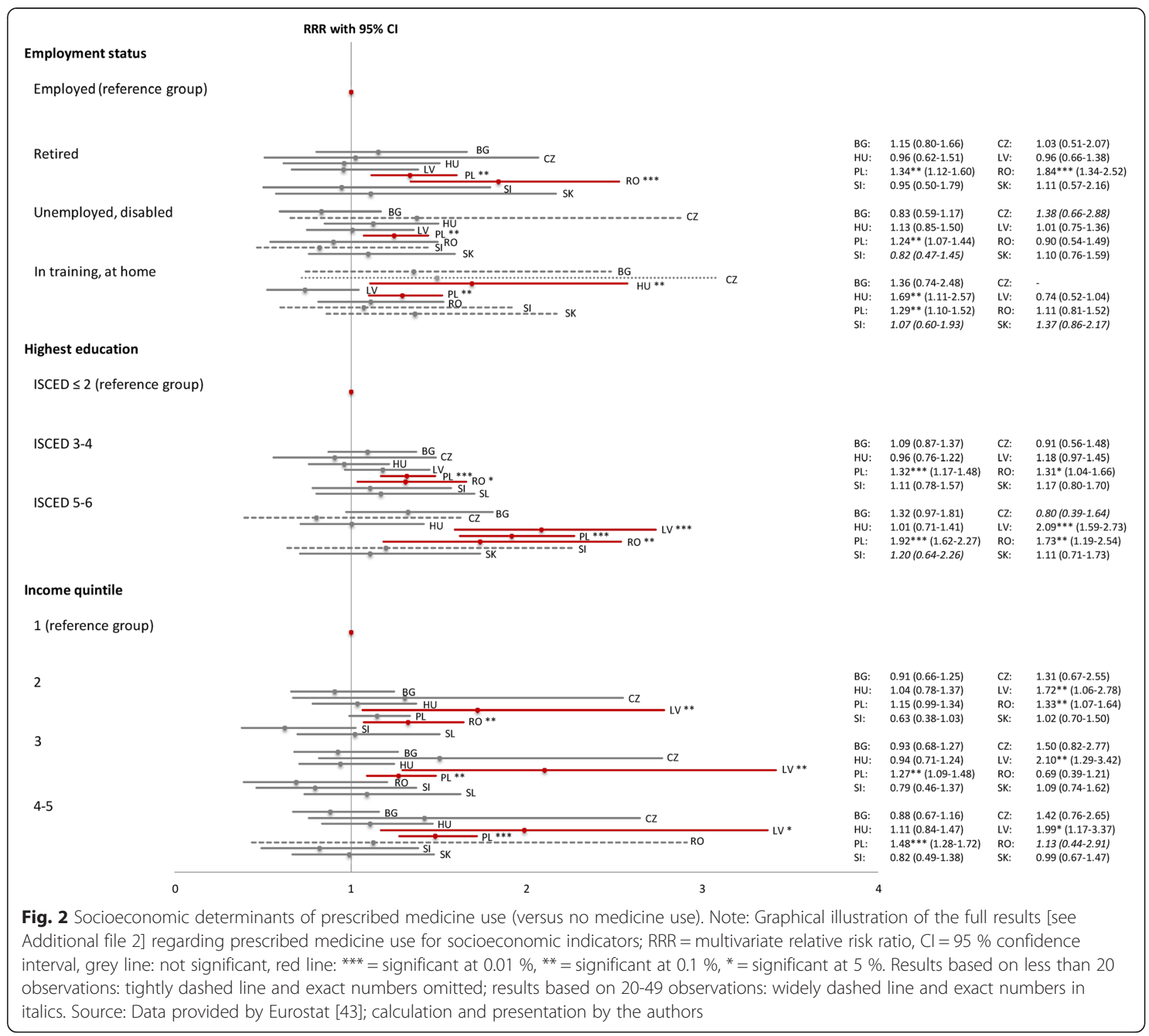

reimbursable medicines (i.e. medicines whose cost were, at least, partially covered by public payers). Market shares for non-prescription and self-medication medicines were higher than in Western European countries [53-55]. Whereas no co-payments were applied in the in-patient sector in the CEECs, they were charged for out-patient medicines: Some countries had prescription fees, and all CEECs applied co-payments as percentage of the price for those medicines that displayed a lower therapeutic value. De-listings (i.e. exclusion of medicines from reimbursement) were reported for some CEECs, and they contributed to increased private pharmaceutical expenditure.

The number of authorized medicines and of medicines on the market was usually lower in the CEECs than in the other European countries (for data on Europe see
[9]). Except for Slovenia, pharmacy density was higher in the surveyed CEECs than in Western European countries (an average of 3,360 and 5,780 inhabitants per pharmacy in the EU-10 and the EU-15 respectively in 2005, [9]). But major intra-country discrepancies resulting in low accessibility to pharmacies in the rural areas existed in some CEECs (Bulgaria, Czech Republic, Poland, Romania). The sale of (specific) OTC medicines outside pharmacies was permitted in all surveyed CEECs but Latvia, Poland and Slovakia.

Pricing and reimbursement is a national competence in the EU Member States under the condition that overall procedural provisions, as laid down in the EU Transparency Directive [56] such as deadlines for pricing and reimbursement decisions, for instance, are complied with. The CEECs adapted their pricing and reimbursement 
systems to the 'acquis communitaire' before acceding to the EU in 2004 and 2007, respectively [57]. Some CEECs (Czech Republic, Slovenia, Slovakia) undertook additional changes in the years before the EHIS survey, to further strengthen their institutional framework and/or to react to new challenges, such as high-cost medicines [see country profiles in Additional file 1]. At the time of the survey, Poland was fundamentally changing its pharmaceutical pricing and reimbursement system following a European Commission's infringement procedure related to the EU Transparency Directive that also addressed long decision times. Related to demand-side measures, measures to encourage rational prescribing and use of medicines, including a promotion of generics' uptake, were in place in the CEECs, but limited enforcement was reported.

Overall, the literature review identified several key challenges and shortcomings in the pharmaceutical systems of the investigated CEECs: In all countries but Slovenia high co-payments and out-of-pocket payments as well a limited enforcement of measures to promote a more rational prescribing and use of medicines (including encouraging generics uptake) were an issue. Underfunding of the pharmaceutical system was reported from Bulgaria, the Czech Republic, Latvia and Romania, and informal payments on a major scale were identified in Bulgaria, Hungary, Latvia, Poland, and Romania. Bulgaria, Poland and Romania were criticized for inefficiencies in procedures and policy coordination. Slovenia was the only country out of the eight CEECs for which the abovementioned deficits were not reported. However, Slovenia was struggling with limited availability of medicines, and so did Bulgaria, Latvia and Romania.

\section{Discussion}

According to the analysis of EHIS survey data higher socioeconomic groups were found to have a comparably higher likelihood to use non-prescribed medicines in all eight surveyed CEECs and to use prescribed medicines in three countries (Latvia, Poland, and Romania). Our findings are partly in line with the very few studies on this issue: Geckova et al. [19] found a pro-rich socioeconomic gradient in non-prescribed medicine use and a pro-poor gradient in prescribed medicine use of adolescents in Slovakia in 1998. Gorecka et al. [20] identified geographic variation in the use of cardiovascular medicines level in the Czech Republic for the years 19972000 and attributed this to socioeconomic factors.

The eight CEECs have a social health insurance system in place that should, in principle, ensure coverage of the entire population and would allow linking health related social exclusion to the social policy context which is considered important [57]. The identified socioeconomic inequalities, particularly to prescribed medicine use, might result from deficits in the social insurance systems (issues of non-participation were reported for some CEECs (e.g. Bulgaria: [58]) and from lack of or inefficiencies in specific pharmaceutical policies. In the following, we explore potential factors that are able to contribute to the socioeconomic (in)equalities observed.

\section{Sustainable funding}

A major prerequisite for equitable access to medicines is sustainable funding $[38,42]$. The comparably low pharmaceutical expenditure in Romania ( $€ 92$ per capita) and Bulgaria ( $€ 110$ per capita), but also Latvia and Poland (around $€ 135$ per capita) points to possible underfunding. Insufficient investment in the field of medicines could be one explanation for the socioeconomic gradient in prescribed medicine use observed in Latvia, Poland and Romania. The more than 50 \% increase in per capita pharmaceutical expenditure in Latvia, Romania, Slovakia and Bulgaria in the three years before the survey could be interpreted as countries' efforts to invest into medicines, but it might also be an indicator that the countries spent more than their economic situation allowed and thus negatively impacted sustainability.

\section{Affordability}

Apart from Slovakia, all above mentioned countries had shares of private pharmaceutical expenditure of more than $55 \%$ (Bulgaria as high as $82 \%$ ). The high patients' contributions in Latvia, Romania and Poland are likely a major reason for the non-use of non-prescribed, privately funded medicines, but they might also explain the socioeconomic gradient in prescribed medicine use observed in these countries since patients were frequently required to co-pay for out-patient prescribed medicines. Further co-payments in health care could be additional barriers for patients with a lower socioeconomic background to visit a doctor and get a prescription: In the CEECs co-payments for attending a physician were, generally, in place, supplemented by 'under-the-table payments'.

Overall economic developments are key drivers for policy-makers to curb publicly financed expenditure, even more with the global financial crisis. The Czech Republic, for instance, introduced co-payments to doctors' visits and significantly increased the value-added tax (VAT) on medicines in 2008, and the share of the private pharmaceutical spending had grown by $57 \%$ within three years. This could explain the socioeconomic gradient in non-prescribed use, and it might also lead to socioeconomic inequalities in prescribed medicine use though this was not confirmed by the EHIS results on the Czech Republic.

Within the CEECs Latvia, Hungary and Romania were particularly impacted by the global financial crisis [59]. Latvia responded through several cost-containment 
measures $[60,61]$. This probably aggravated existing socioeconomic inequalities whose existence in health care (not medicines) had been identified as extensive in Latvia, also in comparison to the other Baltic countries [62]. In Romania, accessibility to prescribed, reimbursable medicines was strongly limited at the time of the survey due to high co-payments for out-patient medicines, and particularly due to the existence of pharmaceutical budgets for pharmacies: Once a monthly financial threshold had been reached a pharmacy was no longer permitted to fill prescriptions [63]. Thus, patients could not access prescribed medication unless they were willing, and able, to pay for it out-of-pocket. In 2007, after years of galloping growth rates in pharmaceutical expenditure, Hungary launched a reform to drastically curb public pharmaceutical expenditure. As a result, the share of private pharmaceutical expenditure (52\%) was rather high at the time of the survey (2009), and it had considerably grown (by $38 \%$ ) within the previous three years. This may cause concerns about limited affordability for lower socioeconomic groups [28]. Despite this austere cost-containment strategy no socioeconomic gradient in prescribed medicine use was found. A possible explanation is provided by a study on Hungary [64] according to which affordability of medicines was not negatively impacted by the cost-containment measures. It was argued that the policies were designed in a way to particularly target market participants (industry, distribution actors) rather than private households. Medicine prices were drastically cut, for instance, but this resulted in lower (percentage) co-payments for the patients.

Medicine prices should be affordable for those who pay for them - public payers and private households. There is lack of knowledge about prices of OTC medicines in general [65], and these prices have not been surveyed in the CEECs either. The socioeconomic gradient in non-prescribed medicine use that was found in all eight CEECs potentially implies that patients with a lower socioeconomic background considered medicines, which had to be paid out-of-pocket, as not affordable. In this context, attention should be paid to the value-added $\operatorname{tax}$ (VAT) on medicines. In many low- and middleincome countries world-wide, taxes and duties account for a considerable share of the medicine prices, thus contributing to increasing medicine prices up to an unaffordable level for the majority of the population [66]. In the CEECs, the only relevant tax related to the price of a medicine is the value-added tax. In the CEECs the VAT rates on medicines (amounting to $10 \%$ or less) tended to be lower than the standard VAT rates $[9,67]$ and lower compared to the other EU countries. Nonetheless, they had risen in some countries (Czech Republic, Poland, Romania, Slovenia) from usually $5 \%$ in 2004 [7] to their current rates of between 7.5 and $10 \%$ since an increase in VAT rates was a common costcontainment policy [60]. While it might not appear high, it might still result in a medicine price of non-funded medicines that lower socioeconomic groups were not able, or not willing, to afford.

Little can be said about whether medicine prices were affordable for public payers in the CEECs given the lack of price studies in this region. One study [68] on 23 European countries that also included six CEECs showed that the pharmacy retail price (i.e. price at pharmacy) in the CEECs, except for Slovenia, was considerably lower than in the other European countries. However, unpublished analyses from the Pharma Price Information service of the Austrian Public Health Institute [69] indicated that at the time of the EHIS survey prices for specific new, high-cost medicines (e.g. cancer medicines, orphan medicines) were comparably high. These medicines were typically fully funded by public payers, and this ensured access to higher-priced medicines for the patients. This might explain why a socioeconomic gradient for prescribed medicine use was found in only three of the eight CEECs included in our study.

\section{Availability and accessibility}

Limited medicine availability was an issue in the CEECs. However, availability deficits were apparently not linked to the socioeconomic background of the patients, but targeted the whole population, as in the case of Slovenia and Latvia with a low number of medicines authorized and/or on the market. These countries are considered as 'small markets' that might not be sufficiently attractive for the pharmaceutical industry to be supplied [70]. Limited availability also resulted from medicine shortages, i.e. that medicines were not supplied in sufficient quantity to pharmacies and hospitals. This was reported to be a major problem in Romania [71]. Furthermore, we found indications of regional inequalities: Despite the generally high pharmacy density in the CEECs (except for Slovenia), major intra-country discrepancies existed in some CEECs (Bulgaria, Czech Republic, Poland, Romania) and resulted in low accessibility to pharmacies in the rural areas. Regarding the regional variation of OTC retailers, based on the experience from Western European countries about a clustering of these dispensaries in towns with already good accessibility [65], it can be assumed that the easier access to OTC medication was likely to primarily serve well-off people in the urban areas who were willing and able to pay for these nonfunded medicines. This would contribute to regional inequalities within countries, but depending on the regional distribution of socioeconomic groups can also contribute to the socioeconomic gradient identified in this paper. 


\section{Rational selection and use of medicines}

A major need for improving the pricing and reimbursement procedure was reported from Bulgaria and Romania whose processes were considered unclear and intransparent. The design of a pricing and reimbursement system is not simply a technical issue but it can considerably impact accessibility and affordability: Unclear and intransparent processes encourage corruption and an irrational selection of medicines into reimbursement, and this, eventually, can limit sustainable public funding. Cumbersome long processes, as observed for Poland, might result in delays in access to needed medicines for patients.

The CEECs have been criticized for not paying enough attention to promoting a rational use of medicines [57] that aims to ensure that patients receive the appropriate medicine at the right dose and at the time they require. The instruments to encourage rational prescribing existed in the CEECs but were apparently not fully enforced. Knowing this, however, we cannot draw conclusions as to whether the medicine use reported in the EHIS survey was appropriate, or not.

Given the limits in funding by both public payers and private households, promoting the uptake of generics is considered as a recommended policy option [72]. The CEECs already had comparably high generic market shares, since local generic industries played a strong role historically, even before the transition process [73], and the use of prescribed generics was promoted by tools such as INN prescribing and generic substitution. Still, high reluctance versus the quality of generics was reported [12]. Thus, awareness-raising campaigns to inform about generics could be a policy to reduce in the observed socioeconomic gradient in non-prescribed use, by motivating people to use lower priced generics.

\section{Reducing socioeconomic inequalities through pharmaceutical policies?}

Summarizing, the policy analysis identified some factors that help explain the observed socioeconomic gradient in non-prescribed medicine use in the eight CEECs and in prescribed medicine use in three of them. These include a high and increasing share of private funding such as co-payments for prescribed out-patient medicines and co-payments beyond medicines (e.g. for attending doctors to get a prescription), limited investment in medicines, and long and intransparent processes regarding the inclusion of medicines into reimbursement. Further deficits such as limited availability of medicines, irrational prescribing and regional variation in the accessibility of pharmacies and OTC retailers are additional factors limiting an equitable access but it could not be determined whether, or not, lower socioeconomic groups are particularly affected. The analysis of the pharmaceutical policies in Latvia, Poland and Romania provides an indications that actually these policies contribute to the observed socioeconomic inequalities in prescribed medicine use in these countries. While the three countries cannot be seen as a very homogenous cluster in terms of pharmaceutical policies, they share an accumulation of policies that do not adequately address inequalities in medicines use. Similarly, for Bulgaria, the policy framework observed would suggest a socioeconomic gradient in prescribed medicine use. This, however, was not confirmed based on the EHIS data. Also, it might have been possible that costcontainment policies would have had a negative impact on equitable access to medicines in the Czech Republic and in Hungary. In this respect, note that the only two other studies $[19,20]$ on socioeconomic determinants in medicine use in CEECs, focussing on adolescents in Slovakia and on cardiovascular medicines in Czech Regions did identify a socioeconomic gradient. Though pharmaceutical policies were apparently successful in reducing socioeconomic inequalities in medicine use in some CEECs, further factors were likely to have an impact. These might be factors at the individual level of the patients (e.g. adherence to medicines) as well as overall political and economic factors, such as the stability of a health care system, patients' trust into it and the impact of the transition processes as observed in the CEECs in the 1990-ties. Finally, the non-existence of a socioeconomic gradient in medicine use can still imply any under-use, over-use or misuse of medicines in general, and overall limited availability and accessibility of medicines for the patients of that country.

\section{Limitations}

This study does not come without limitations. First, the quantitative analysis is based on self-reported information and hence comes with a risk of measurement errors. However, at the individual country level, where data was collected, several quality control steps were taken [74] and data comparability was also ensured by Eurostat, based e.g. on a standard questionnaire, conceptual guidelines and rationales as well as a standard translation protocol $[75,76]$. Data was collected either via a stand-alone survey or as part of another (health or nonhealth) survey (i.e. national health interview survey, labour force survey, other household survey) based on face-toface interviews, telephone interviews, self-administered questionnaires (or a combination of these means) [77]. Consistency and integrity checks on the national EHIS data were carried out by Eurostat, and quality reports were also disseminated [74]. Also, household surveys are an acknowledged standard tool in pharmaceutical consumption research according to the WHO [78]. Second, the EHIS household surveys goes beyond the regulatory definition of medicines in national legislations since 
'dietary supplements such as herbal medicines or vitamins' were part of a question on medicine use (Table 3). To find out if this influences our results, sensitivity analyses were carried out excluding both the use of 'vitamins, minerals or tonics' or/and 'some other type or medicine or supplement', respectively. While the socioeconomic gradient was generally found to be less pronounced but still statistically significant in these sensitivity analyses, the qualitative conclusions regarding the socioeconomic gradient identified in the main analysis remained the same. Third, interviewees were asked about their use of 'medicines prescribed or recommended by a doctor' and 'medicines not prescribed or recommended by a doctor' (Table 3). Since we had no information about medicines recommended but not prescribed, we interpreted these two categories of 'prescribed' and 'non-prescribed use'. We based this approach on the assumption that doctors tend to believe that patients expect a prescription [79]. Fourth, the analysis refers to different time periods between 2007 and 2009. We investigated the pharmaceutical policy framework at the time of the EHIS survey at national level, but for comparing national data (e.g. expenditure) versus a European or CEE average a specific year (2008) was taken as reference. This was, in some cases, not the year of the survey. Also, the survey comes with different national sample sizes. This seems especially relevant for Poland, where the analysis is based on a comparatively large study population, and thus even small differences between socioeconomic groups may become statistically significant. Finally, non-use of medicines can have numerous causes. We explored whether the pharmaceutical policy framework impacts, positively or negatively, on socioeconomic (in)equalities. However, as the wealth of literature on adherence rightly points out, there are several other reasons for not using medicines or stopping prescribed medication prematurely. To identify the relative importance of the various factors as co-determinants of the use or non-use of medicines, in-depth investigation for single countries is needed in future research.

\section{Conclusion}

Our study confirmed a socioeconomic gradient in medicine use in Central and Eastern Europe: Socioeconomic inequalities in non-prescribed medicine use were found in all eight surveyed CEECs, whereas for prescribed medicines this was only the case in three countries (Latvia, Poland, and Romania). The latter could be an indication that pharmaceutical policies, which typically refer to publicly (co-)funded medicines, had been able to successfully address inequalities in the other CEECs. Increasing public funding for medicines, and reductions in and exemptions from co-payments for vulnerable groups are likely appropriate strategies to ensure more equitable access to medicines. In addition, an increased generics uptake, a more rational selection of medicines into reimbursement and more rational prescribing can contribute to raise resources for public spending.

Our study confirms that pharmaceutical policies, and their implementation and enforcement, are important tools to address socioeconomic inequalities. As a more general conclusion, with improved knowledge about the extent and the character of socioeconomic inequalities in medicine consumption in CEECs as well as in other parts of the world, pharmaceutical policies could be used more effectively as a major tool to improve access to medicines across entire populations.

This study refers to the years 2007-2009. Meanwhile, the CEEC region has been severely affected by the global financial crisis. The economic situation has led to increasing poverty and growing financial pressure for large parts of the populations, which, not least, can lead to changes in medicine consumption. Further, public budgets came under increasing pressure, a pressure that also tightens financial scope for pharmaceutical policies. For future research, it is suggested to follow up this study by analysing pharmaceutical policies in the CEECs during the crisis and exploring their impact on medicine use.

\section{Additional files}

Additional file 1: Table $\mathbf{S 1}$. Prescribed medicine use, non-prescribed medicine use, medicine use of both types versus no medicine use; description of data: Full results for multinomial logistic regression analyses for eight individual countries. (DOCX $47 \mathrm{~kb}$ )

Additional file 2: Table S2. Background information on pharmaceutical policies in 8 Central and Eastern European countries; description of data: Country background information giving an overview of pharmaceutical policies as well as key challenges by country. Sources: All: [49]; Bulgaria: [7, 10, 58, 83, 101, 118]; Czech Republic: [7, 9, 10, 82, 100, 109, 110, 113, 120, 121]; Hungary: $[10,12,16,21,64,85,91,104,106,119,121]$; Latvia: $[60,86,88,102,107,114,122]$; Poland: $[8,95,96,103,111,115,123,124]$; Romania: $[9,10,63,71,84,89,92,94,97,98,125]$; Slovenia: $[7,9,10,70$, 81, 126, 127]; Slovakia: [85, 100, 105, 108, 116, 128,129]. (DOCX 30 kb)

\section{Abbreviations}

(T)HE: (total) health care expenditure; (T)PE: (total) pharmaceutical expenditure; BG: Bulgaria; CEE(CS): Central and Eastern European (countries); Cl: Confidence interval; CZ: Czech Republic; D: Deductible; EHIS: European Health Interview Survey; EU: European Union; GPs: General practitioners; HC system: Health care system; HU: Hungary; INN: International Non-Proprietary Name; ISCED: International Standard Classification of Education; LV: Latvia; OECD: Organisation for Economic Co-operation and Development; OTC: Over-the-Counter medicines; PE: Pharmaceutical expenditure; PF: Prescription fee; PL: Poland; PP: Percentage points; PPRI: Pharmaceutical Pricing and Reimbursement Information; R: Reimbursement; RO: Romania; RRR: Relative-risk ratio; SI: Slovenia; SK: Slovakia; VAT: Value-added tax; WHO: World Health Organization.

\section{Competing interests}

The authors declare that they have no competing interests.

\section{Authors' contributions}

SV participated in the design of the study, was responsible for the collection of policy information, performed the policy analysis, interpreted the results and drafted the respective sections. AÖ participated in the design of the study, developed the framework section, interpreted the results and drafted 
the respective sections. SM participated in the design of the study, was responsible for the collection of the EHIS data, carried out the quantitative analysis, interpreted the results and drafted the respective sections. Analysis and interpretation of the results were regularly discussed among the authors. All authors read and approved the final manuscript.

\section{Acknowledgements}

The authors gratefully acknowledge the feedback by the participants of the first ATHEA conference (28 November 2014) in Vienna. The authors are also grateful to the members of the Pharmaceutical Pricing and Reimbursement Information (PPRI) network - representatives of competent authorities for pharmaceutical pricing and reimbursement and public payers from today 45 , mainly European countries. Several of them were authors of the PPRI Pharma Profiles and information providers of unpublished data on Central and Eastern European countries, which were fed into the pharmaceutical policy analysis. Finally, the authors gratefully acknowledge the constructive comments made by three anonymous reviewers.

\section{Author details}

'Department of Health Economics, WHO Collaborating Centre for Pricing and Reimbursement Policies, Gesundheit Österreich GmbH (Austrian Public Health Institute), Vienna, Austria. ${ }^{2}$ Department of Socioeconomics, Institute for Social Policy, Vienna University of Economics and Business, Vienna, Austria. ${ }^{3}$ Department of Health Economics, Centre for Public Health, Medical University of Vienna, Kinderspitalgasse 15/1, 1090 Vienna, Austria.

\section{Received: 2 April 2015 Accepted: 29 October 2015} Published online: 05 November 2015

\section{References}

1. WHO. The selection and use of essential medicines. Report of the WHO Expert Committee, 2002 (including the 12th Model list of essential medicines). World Health Organ Tech Rep Ser. 2003;914:i-vi. 1-126.

2. Hogerzeil HV. The concept of essential medicines: lessons for rich countries. BMJ. 2004;329(7475):1169-72.

3. Etienne C, Asamoa-Baah A, Evans DB. Health systems financing: the path to universal coverage. Geneva: World Health Organization; 2010.

4. Pignatti F, Boone $H$, Moulon I. Overview of the European regulatory approval system. J Ambul Care Manage. 2004;27(2):89-97.

5. Rechel B, McKee M. Health reform in Central and Eastern Europe and the former Soviet Union. Lancet. 2009;374(9696):1186-95.

6. Nuijten MJC. Health care reform in xix Central European countries: A focus on health economic requirements in the drug pricing and reimbursement processes. Eur J Health Econ. 2003;4(4):286-91.

7. Vogler S, Antony K, Leopold C, Habl C. Pharmaceutical systems in the new EU member states. Vienna: Österreichisches Bundesinstitut für Gesundheitswesen (ÖBIG); 2005.

8. Vogler S, Habl C, Bogut M, Voncina L. Comparing pharmaceutical pricing and reimbursement policies in Croatia to the European Union Member States. Croat Med J. 2011;52(2):197.

9. Vogler S, Habl C, Leopold C, Rosian-Schikuta I, de Joncheere K, Lyager T. PPRI Report. Vienna: Pharmaceutical Pricing and Reimbursement Information (ÖBIG); 2008

10. Habl C, Antony K, Arts D, Entleitner M, Fröschl B, Leopold C, et al. Surveying, assessing and analysing the pharmaceutical sector in the $25 \mathrm{EU}$ member states. Country profiles. Vienna: Österreichisches Bundesinstitut für Gesundheitswesen (ÖBIG); 2006.

11. Vogler $\mathrm{S}$. The impact of pharmaceutical pricing and reimbursement policies on generics uptake: implementation of policy options on generics in 29 European countries - an overview. GaBI Journal. 2012;1(2):44-51.

12. Habl C, Vogler S, Leopold C, Schmickl B, Fröschl B. Referenzpreissysteme in Europa. Analyse und Umsetzungsvoraussetzungen für Österreich [Reference price systems in Europe. Analysis and lessons learned for implementation in Austria]. Vienna: Österreichisches Bundesinstitut für Gesundheitswesen (ÖBIG); 2008. http://whocc.goeg.at/Literaturliste/Dokumente/BooksReports/ EB_RPS 31 3_08.pdf. Accessed 2 September 2014.

13. Carone G, Schwierz C, Xavier A. Cost-containment policies in public pharmaceutical spending in the EU. Brussels: European Commission, Directorate-General for Economics and Financial Affairs; 2012. http:// ec.europa.eu/economy_finance/publications/economic_paper/2012/ ecp461_en.htm. Accessed 26 May 2014.
14. Balabanova D, McKee M. Understanding informal payments for health care: the example of Bulgaria. Health Policy. 2002;62(3):243-73.

15. Ensor T. Informal payments for health care in transition economies. Soc Sci Med. 2004;58(2):237-46.

16. Gaál P, McKee M. Fee-for-service or donation? Hungarian perspectives on informal payment for health care. Soc Sci Med. 2005;60(7):1445-57.

17. Lewis MA. Who is paying for health care in Eastern Europe and Central Asia? Washington, DC: World Bank Publications; 2000.

18. OECD. Health at a glance 2013: OECD indicators. Paris: OECD Publishing; 2013. http://www.oecd.org/els/health-systems/Health-at-a-Glance-2013.pdf. Accessed 20 September 2015.

19. Geckova AM, van Dijk JP, Zezula I, Tunistra J, Groothoff JW, Post D. Socioeconomic differences in health among Slovak adolescents. Sozial- und Präventivmedizin. 2004:49(1):26-35.

20. Gorecka K, Linhartova A, Vlcek J, Tilser I. Cardiovascular drug utilisation and socio-economic inequalities in 20 districts of the Czech Republic. Eur J Clin Pharmacol. 2005;61(5-6):417-23.

21. Baji P, Pavlova M, Gulácsi L, Groot W. Changes in equity in out-of-pocket payments during the period of health care reforms: evidence from Hungary. Int J Equity Health. 2012;11(1):1-11.

22. Bonfrer I, Van de Poel E, Grimm M, Van Doorslaer E. Does the distribution of healthcare utilization match needs in Africa? Health Policy Plan. 2014;29(7):921-37.

23. Devaux $M$, de Looper $M$. Income-related inequalities in health service utilisation in 19 OECD countries, 2008-2009. Paris: Organisation for Economic Co-operation and Development (OECD); 2012.

24. Lu J, Leung GM, Kwon S, Tin KY, Van Doorslaer E, O'Donnell O. Horizontal equity in health care utilization evidence from three high-income Asian economies. Soc Sci Med. 2007;64(1):199-212.

25. Tchicaya A, Lorentz N. Socioeconomic inequalities in the non-use of dental care in Europe. Int J Equity Health. 2014;13:7.

26. Pinilla J, Negrín-Hernández MA, Abásolo I. Time trends in socio-economic inequalities in the lack of access to dental services among children in Spain 1987-2011. Int J Equity Health. 2015;14(1):9.

27. Mayer S, Österle A. Socioeconomic determinants of prescribed and nonprescribed medicine consumption in Austria. Eur J Public Health. 2015;25(4):597-603.

28. Daban F, Pasarín IM, Rodríquez-Sanz M, García-Altés A, Villalbí JR, Zara C, et al. Social determinants of prescribed and non-prescribed medicine use. Int J Equity Health. 2010;9:12.

29. Ward PR, Noyce PR, St Leger AS. Exploring the equity of GP practice prescribing rates for selected coronary heart disease drugs: a multiple regression analysis with proxies of healthcare need. Int J Equity Health. 2005;4:3.

30. Rechel B, Blackburn CM, Spencer NJ, Rechel B. Access to health care for Roma children in Central and Eastern Europe: findings from a qualitative study in Bulgaria. Int J Equity Health. 2009:8:24.

31. Andersen RM. Behavioral model of families' use of health services. Chicago: Center for Health Administration Studies, University of Chicago; 1968.

32. Babitsch B, Gohl D, von Lengerke T. Re-revisiting Andersen's behavioral model of health services use: a systematic review of studies from 1998-2011. GMS Psycho-Social-Medicine. 2012;9

33. Andersen RM. Revisiting the behavioral model and access to medical care: does it matter? J Health Soc Behav. 1995;36(1):1-10.

34. Nordin M, Dackehag M, Gerdtham U-G. Socioeconomic inequalities in drug utilization for Sweden: evidence from linked survey and register data. Soc Sci Med. 2013;77:106-17.

35. Penchansky R, Thomas JW. The concept of access: definition and relationship to consumer satisfaction. Med Care. 1981;19(2):127-40

36. Centre for Pharmaceutical Management. Access to essential drugs, vaccines, and health commodities: report of the WHO-MSH consultative meeting. France: Ferney-Voltaire; 2003.

37. Frost $L$, Reich M. How do good health technologies get to poor people in poor countries. Boston, MA: Harvard Center for Population and Development Studies; 2010.

38. Bigdeli M, Jacobs B, Tomson G, Laing R, Ghaffar A, Dujardin B, et al. Access to medicines from a health system perspective. Health Policy Plan. 2013;28:692-704.

39. Gemmill MC, Thomson S, Mossialos E. What impact do prescription drug charges have on efficiency and equity? Evidence from high-income countries. Int J Equity Health. 2008;7:12. 
40. Leopold C, Mantel-Teeuwisse AK, Vogler S, Valkova S, de Joncheere K, Leufkens $\mathrm{HG}$, et al. Effect of the economic recession on pharmaceutical policy and medicine sales in eight European countries. Bull World Health Organ. 2014;9(92):630-40.

41. Leopold C, Zhang F, Mantel-Teeuwisse AK, Vogler S, Valkova S, Ross-Degnan $D$, et al. Impact of pharmaceutical policy interventions on utilization of antipsychotic medicines in Finland and Portugal in times of economic recession: interrupted time series analyses. Int J Equity Health. 2014;13(1):53.

42. WHO. Equitable access to essential medicines: a framework for collective action. Geneva: World Health Organization (WHO); 2004. http://apps.who.int/ medicinedocs/pdf/s4962e/s4962e.pdf. Accessed 1 September 2015.

43. Eurostat. European Health Interview Survey (EHIS) - Eurostat metadata. 2014. http://ec.europa.eu/eurostat/cache/metadata/en/hlth_det_esms.htm. Accessed 1 September 2015.

44. Eurostat. EHIS data collection - surveys overview. 2012. http://ec.europa.eu/ eurostat/cache/metadata/Annexes/hlth_det_esms_an1.pdf. Accessed 1 September 2015

45. De Looper M, Lafortune G. Measuring disparities in health status and in access and use of health care in OECD countries. Paris: Organisation for Economic Co-operation and Development (OECD); 2009.

46. Mackenbach JP, Stirbu I, Roskam A-JR, Schaap MM, Menvielle G, Leinsalu M, et al. Socioeconomic inequalities in health in 22 European countries. N Engl J Med. 2008:358(23):2468-81.

47. Vogler S, Espin J, Habl C. Pharmaceutical Pricing and Reimbursement Information (PPRI) - New PPRI analysis including Spain. Pharma Policy Law. 2009;11(3):213-34

48. Vogler S, Leopold C, Zimmermann N, Habl C, de Joncheere K. The Pharmaceutical Pricing and Reimbursement Information (PPRI) initiative experiences from engaging with pharmaceutical policy makers. Health Policy Tech. 2014;3(2):139-48

49. Eurostat. Eurostat health database. 2014. http://ec.europa.eu/eurostat/ statistics-explained/index.php/Healthcare_statistics. Accessed 3 November 2015.

50. Knoepfel P, Larrue C, Varone F, Hill M. Public policy analysis. Bristol: Policy Press; 2011.

51. Eggen AE. Patterns of medicine use in a general population ( $0-80$ years) The Influence of age, gender, diseases and place of residence on drug use in Norway. Pharmacoepidem Dr S. 1997;6(3):179-87.

52. OECD. OECD Health Data. Paris: Organisation for Economic Co-operation and Development (OECD); 2014.

53. AESGP. Economic and legal framework for non-prescription medicines. Brussels: Association of the European Self-Medication Industry (AESGP); 2008.

54. AESGP. Economic and legal framework for non-prescription medicines. Brussels: Association of the European Self-Medication Industry (AESGP); 2010.

55. AESGP. Economic and legal framework for non-prescription medicines. Brussels: Association of the European Self-Medication Industry (AESGP); 2009.

56. European Commission. Council Directive 89/105/EEC of 21 December 1988 relating to the transparency of measures regulating the pricing of medicinal products for human use and their inclusion in the scope of national health insurance systems Brussels. 1989. http://ec.europa.eu/health/files/eudralex/ vol-1/dir_1989_105/dir_1989_105_en.pdf. Accessed 21 June 2014.

57. Walley T, Mossialos E, Mrazek M, de Joncheere C. Supply and regulation of medicines. Br Med J. 2005;331(7510):171-2.

58. Rechel B, Blackburn CM, Spencer NJ, Rechel B. Regulatory barriers to equity in a health system in transition: a qualitative study in Bulgaria. BMC Health Serv Res. 2011;11(1):219.

59. Terazi $\mathrm{E}$, Senel $\mathrm{S}$. The effects of the global financial crisis on the central and eastern European Union countries. Int Bus Soc Sci. 2011;2(17):186-92.

60. Vogler S, Zimmermann N, Leopold C, de Joncheere K. Pharmaceutical policies in European countries in response to the global financial crisis South Med Rev. 2011:4(2):32.

61. Buysse I. Impact of the economic recession on the pharmaceutical sector. Utrecht: Utrecht University, WHO Collaborating Centre for Pharmacoepidemiology \& Pharmaceutical Policy Analysis; 2010. http:// www.pharmaceuticalpolicy.n//Publications/Reports/ Buysse_report\%20impact\%20recession_2010.pdf. Accessed 21 June 2014.

62. Habicht J, Kiivet R-A, Habicht T, Kunst AE. Social inequalities in the use of health care services after 8 years of health care reforms-a comparative study of the Baltic countries. Int J Public Health. 2009:54(4):250-9.
63. Leopold C, Vogler S. Access to essential medicines in Romania. Vienna: Österreichisches Bundesinstitut für Gesundheitswesen (ÖBIG); 2010.

64. Hren R. Impact of the Pharma Economic Act on diffusion of innovation and reduction of costs in the Hungarian prescription drug market (2007-2010). ViHRI. 2013;2(2):290-9.

65. Vogler S, Habimana K, Arts D. Does deregulation in community pharmacy impact accessibility of medicines, quality of pharmacy services and costs? Evidence from nine European countries. Health Policy. 2014;117(3):311-27.

66. Creese A. Sales taxes on medicines. Working paper 5, WHO/HAl Project on Medicine Prices and Availability, review series on pharmaceutical pricing policies and interventions: World Health Organization (WHO) and Health Action International (HAl). 2011. http://www.haiweb.org/medicineprices/ 05062011/Taxes\%20final\%20May2011.pdf. Accessed 21 June 2014.

67. OECD. Pharmaceutical pricing policies in a global market. Paris: Organisation for Economic Co-operation and Development (OECD); 2008. http:// whocc.goeg.at/Literaturliste/Dokumente/FurtherReading/ Pharmaceutical\%20Pricing\%20Policies\%20in\%20a\%20Global\%20Market.pdf. Accessed 10 August 2014.

68. Walter E. Der österreichische Pharmamarkt: ein europäischer Vergleich The Austrian Pharma Market: A European Comparison]. Vienna: Institut für Pharmaökonomische Forschung (IPF); 2008.

69. Gesundheit Österreich GmbH. Pharma Price Information (PPI) service. Vienna; 2004-2014. http://www.goeg.at/en/PPI. Accessed 3 November 2015.

70. HMA. Report of Task Force of Heads of Medicines Agencies (HMA): Availability of human medicinal products. Madeira: Heads of Medicines Agencies (HMA); 2007. http://ec.europa.eu/health/files/committee/ 73meeting/73plus/hma.pdf. Accessed 8 August 2014.

71. Gheonea V, Constandache N, Roman G. Romanian health care reform in the context of economic crisis. Acta Universitatis Danubius Economica. 2010;6(4):43-55.

72. WHO. WHO guideline on country pharmaceutical pricing policies. Geneva: World Health Organization (WHO); 2013. http://apps.who.int/medicinedocs/ documents/s21016en/s21016en.pdf. Accessed 23 August 2014.

73. Kazakov R. Pricing and reimbursement policies in new EU accession countries. J Gen Med. 2007;4(4):249-58.

74. Gauci D. Synthesis report on use of EHIS quality assessment criteria. 2011. https://circabc.europa.eu/d/d/workspace/SpacesStore/225d2243-77fc-46579fd0-ee65209bbf8c/Synthesis\%20of\%20national\%20quality\%20reports.pdf. Accessed 9 September 2014.

75. Eurostat. European Health Interview Survey (EHIS) questionnaire. 2006. https://circabc.europa.eu/d/d/workspace/SpacesStore/f1 bbab8c-db6a-4842 ab23-6717a48864ff/EHIS\%20questionnaire\%20EN\%20last\%20version.pdf. Accessed 17 August 2014.

76. Eurostat. European Health Interview Survey (EHIS) 1st round 2007-2009, conceptual translation cards and guidelines. 2009. https://circabc.europa.eu/ d/d/workspace/SpacesStore/bc8680c6-e564-49c6-a6d5-7ddfbf0916f4/ Updated\%20EHIS\%20guidelines\%20May\%202009.pdf. Accessed 20 April 2014.

77. Eurostat. European health interview survey - methodology. 2015. http:// ec.europa.eu/eurostat/statistics-explained/index.php/European_health_ interview_survey_-_methodology. Accessed 28 August 2015.

78. WHO. Manual for the household survey to measure access and use of medicines. 2008. http://www.who.int/medicines/areas/coordination/ household_manual_february_2008.pdf. Accessed 26 May 2014.

79. Britten $\mathrm{N}$, Ukoumunne $\mathrm{O}$. The influence of patients' hopes of receiving a prescription on doctors' perceptions and the decision to prescribe: a questionnaire survey. BMJ. 1997;315(7121):1506-10.

80. Eurostat. EHIS data delivery guidelines. 2010. https://circabc.europa.eu/d/d/ workspace/SpacesStore/7a271d3f-389a-49ac-8317-890add826585/EHIS\%20\%201st\%20round\%202007-2009\%20-\%20Data\%20delivery\%20guidelines\% 20up\%20to\%20date\%20January\%202010.pdf. Accessed 21 June 2015.

81. Albreht T, Turk E, Toth M, Ceglar J, Marn S, Pribaković Brinovec R, et al. Slovenia: Health system review. Health Syst Transit. 2009;11(3):1-168.

82. Bryndová L, Pavloková K, Roubal T, Rokosová M, Gaskins M, van Ginneken E. Czech Republic: Health system review. Health Syst Transit. 2009;11(1):1-122.

83. Dimova A, Rohova M, Moutafova E, Atanasova E, Koeva S, Panteli D, et al. Bulgaria: Health system review. Health Syst Transit. 2012;14(3):1-186.

84. Weigl M, Antony K. Arzneimittelsysteme in Bulgarien und Rumänien [Pharmaceutical systems in Bulgaria and Romania]. Vienna: Österreichisches Bundesinstitut für Gesundheitswesen (ÖBIG); 2008. 
85. Gaál P, Szigeti S, Csere M, Gaskins M, Panteli D. Hungary: Health system review. Health Syst Transit. 2011;13(5):1-266.

86. Mitenbergs U, Taube M, Misins J, Mikitis E, Martinsons A, Rurane A, et al. Latvia: Health system review. Health Syst Transit. 2012;14(8):1-191.

87. Szalay T, Pažitný P, Szalayová A, Frisová S, Morvay K, Petrovič M, et al. Slovakia: Health system review. Health Syst Transit. 2011;13(2):1-174.

88. Tragakes E, Brigis G, Karaskevica J, Rurane A, Stuburs A, Zusmane E. Latvia: Health system review. Health Syst Transit. 2008;10(2):1-253.

89. Vlădescu C, Scîntee G, Olsavszky V, Allin S, Mladovsky P. Romania: Health system review. Health Syst Transit. 2008;10(3):1-172.

90. Delcheva E, Balabanova D, McKee M. Under-the-counter payments for health care: evidence from Bulgaria. Health Policy. 1997;42(2):89-100.

91. Gaál P, Evetovits T, McKee M. Informal payment for health care: evidence from Hungary. Health Policy. 2006;77(1):86-102.

92. Haivas I. Health care in Romania: Fighting collapse. Can Med Assoc J. 2010;182(7):654-5.

93. Szende A, Culyer AJ. The inequity of informal payments for health care: the case of Hungary. Health Policy. 2006;75(3):262-71.

94. Ungureanu MI, Litan CM, Rus IA, Cherecheş RM. A brief insight into the study of informal health care payments in Romania. Transylv Rev Adm Sci. 2013:39:212-9.

95. Łuczak J, García-Gómez P. Financial burden of drug expenditures in Poland. Health Policy. 2012;105(2):256-64.

96. Golinowska S, Tambor M. Out-of-pocket payments on health in Poland: size, tendency and willingness to pay. Soc Econ. 2012;34(2):253-71.

97. Seiter A. Romania: pharmaceutical sector analysis - draft, June 2007. 2007.

98. Oprea L, Gavrilovici C, Anton SG. Ethical issues in financing health care in Romania. Soc Res Rep. 2013;23:19-25.

99. Cockcroft A, Andersson N, Paredes-Solís S, Caldwell D, Mitchell S, Milne D, et al. An inter-country comparison of unofficial payments: results of a health sector social audit in the Baltic States. BMC Health Serv Res. 2008;8(1):15.

100. Baji P, Boncz I, Jenei G, Gulácsi L. Comparing cost-sharing practices for pharmaceuticals and health care services among four central European countries. Soc Econ. 2012;34(2):221-40.

101. Andre G, Semerdjiev I. PPRI Pharma Profile Bulgaria. Vienna: Pharmaceutical Pricing and Reimbursement Information (PPRI); 2007. http://whocc.goeg.at/ Literaturliste/Dokumente/CountrylnformationReports/ Bulgaria_PPRI_2007.pdf. Accessed 9 September 2014.

102. Behmane D, Viksna A, Gulbe A. PPRI Pharma Profile Latvia. Vienna: Pharmaceutical Pricing and Reimbursement Information (PPRI); 2008. http:// whocc.goeg.at/Literaturliste/Dokumente/CountryInformationReports/ Latvia_PPRI_2008.pdf. Accessed 18 August 2014.

103. Janiszewski R, Bondaryk K. PPRI Pharma Profile Poland. Vienna: Pharmaceutical Pricing and Reimbursement Information (PPRI); 2007. http:// whocc.goeg.at/Literaturliste/Dokumente/CountrylnformationReports/ Poland_PPRI_2007.pdf. Accessed 26 May 2014.

104. Kovacs T, Rozsa P, Szigeti S, Borcsek B, Lengyel G. PPRI Pharma Profile Hungary. Vienna: Pharmaceutical Pricing and Reimbursement Information (PPRI); 2007. http://whocc.goeg.at/Literaturliste/Dokumente/CountryInformationReports/ Hungary_PPRI_2007.pdf. Accessed 3 September 2014.

105. Mazag J, Segec A. PPRI Pharma Profile Slovakia. Vienna: Pharmaceutical Pricing and Reimbursement Information (PPRI); 2007. http://whocc.goeg.at/ Literaturliste/Dokumente/CountrylnformationReports/ Slovakia_PPRI_2007.pdf. Accessed 18 August 2014.

106. National Health Insurance Fund. PPRI poster Hungary: Pharmaceutical pricing and reimbursement in the out-patient sector. Vienna: Pharmaceutical Pricing and Reimbursement Information (PPRI); 2009. http:// whocc.goeg.at/Literaturliste/Dokumente/CountrylnformationPosters/ Poster_Berlin09_Hungary.pdf. Accessed 3 July 2014.

107. State Medicines' Pricing and Reimbursement Agency. PPRI poster Latvia: Pharmaceutical pricing and reimbursement in the out-patient sector. Vienna: Pharmaceutical Pricing and Reimbursement Information (PPRI); 2009. http:// whocc.goeg.at/Literaturliste/Dokumente/CountrylnformationPosters/ Poster_Berlin09_Latvia.pdf. Accessed 8 August 2014.

108. State Institute for Drug Control. PPRI poster Slovakia: Pharmaceutical pricing and reimbursement in the out-patient sector. Vienna: Pharmaceutical Pricing and Reimbursement Information (PPRI); 2007.

109. State Institute for Drug Control. PPRI poster Czech Republic: Pharmaceutical pricing and reimbursement in the out-patient sector. Vienna: Pharmaceutical Pricing and Reimbursement Information (PPRI); 2007. http://
whocc.goeg.at/Literaturliste/Dokumente/CountryInformationPosters/ Czech_Republic_Poster.pdf. Accessed 5 May 2014.

110. State Institute for Drug Control. PPRI poster Czech Republic: Pharmaceutical pricing and reimbursement in the out-patient sector. Vienna: Pharmaceutical Pricing and Reimbursement Information (PPRI); 2009. http:// whocc.goeg.at/Literaturliste/Dokumente/CountrylnformationPosters/ Poster_Berlin09_CZ.pdf. Accessed 5 May 2014.

111. Leopold C, Vogler S. Access to essential medicines in Poland. Vienna: Österreichisches Bundesinstitut für Gesundheitswesen (ÖBIG); 2009.

112. Andre G, Semerdjiev I. PHIS hospital pharma report Bulgaria. Vienna: Pharmaceutical Health Information System (PHIS); 2009. Available from: http://whocc.goeg.at/Literaturliste/Dokumente/CountrylnformationReports/ PHIS\%20Bulgaria\%20Hospital\%20Pharma\%20Report\%202009.pdf. Accessed 7 September 2014

113. Zalesakova P. PHIS hospital pharma report Czech Republic. Vienna: Pharmaceutical Health Information System (PHIS); 2009. http:// whocc.goeg.at/Literaturliste/Dokumente/CountrylnformationReports/ PHIS\%20Hospital\%20Pharma\%20Czech\%20Republic\%202009.pdf. Accessed 5 September 2014.

114. Gulbe A, Innus J, Mārtinsons A. PHIS hospital pharma report Latvia. Vienna: Pharmaceutical Health Information System (PHIS); 2009. http:// whocc.goeg.at/Literaturliste/Dokumente/CountrylnformationReports/ PHIS\%20Latvia\%20Hospital\%20Pharma\%20Report\%202009.pdf. Accessed 2 September 2014.

115. Adamski J, Wndykowska K. PHIS hospital pharma report Poland. Vienna: Pharmaceutical Health Information System (PHIS); 2009. http://whocc.goeg.at/ Literaturliste/Dokumente/CountrylnformationReports/PHIS\%2OHospital\%20 Pharma\%20Poland\%202009.pdf. Accessed 21 June 2014.

116. Mazag J. PHIS hospital pharma report Slovakia. Vienna: Pharmaceutical Health Information System (PHIS); 2009. http://whocc.goeg.at/Literaturliste/ Dokumente/CountrylnformationReports/ 7\%20Slovakia\%20Hospital\%20Pharma.pdf. Accessed 18 August 2014

117. Vogler S, Habl C, Leopold C, Mazag J, Morak S, Zimmermann N. PHIS hospital pharma report. Vienna: Pharmaceutical Health Information System (PHIS); 2010.

118. Andre G, Semerdjiev I. PHIS hospital pharma profile Bulgaria. Vienna: Pharmaceutical Health Information System (PHIS); 2010. http:// whocc.goeg.at/Literaturliste/Dokumente/CountrylnformationReports/ PHIS_Pharma_Profile_Bulgaria_Oct2010.pdf. Accessed 2 September 2014.

119. OECD. Competition issue in the distribution of pharmaceuticals. Contribution from Hungary. Paris: Organisation for Economic Co-operation and Development (OECD); 2014. Global Forum on Competition. 27/28 February 2014.

120. Davidova J, Praznovcova L, Lundborg CS. Pricing and reimbursement of pharmaceuticals in the Czech Republic and Sweden. Pharm World Sci. 2008;30(1):57-64.

121. Lörinczy M. Impact of the crisis on the pharmaceutical market in the Czech Republic and Hungary. Forum Scientiae Oeconomia. 2013;1 (2):21-33.

122. van Ginneken E, Habicht J, Murauskiene L, Behmane D, Mladovsky P. The Baltic states: building on 20 years of health reforms. Br Med J. 2012;345, e7348.

123. Sagan A, Panteli D, Borkowski W, Dmowski M, Domański F, Czyżewski M, et al. Poland: Health system review. Health Syst Transit. 2011;13(8):1-193.

124. Simoens S. Developing competitive and sustainable Polish generic medicines market. Croat Med J. 2009:50(5):440-8.

125. Zanfir A, Marinescu M, Sarbu R. The analysis of the current problems and drawbacks in the Romanian health system. Int J Aca Res Econ Manag Sci. 2012;1(6):60-6.

126. Lakić D, Tasić L, Kos M, Petrova G, Stoimenova A, Krajnović D. Pharmacy network and access to medicines in selected eastern European countries: comparative analysis. Croat Med J. 2012;53(1):53-9.

127. Primožič S. Update on changes in Slovenia: Presentation at the 5th PPRI Coordination Meeting, Vienna, 28 June 2007. 2007.

128. Kaló Z, Docteur E, Moïse P. Pharmaceutical pricing and reimbursement policies in Slovakia. Paris: Organisation for Economic Co-operation and Development (OECD); 2008.

129. Nemec J, Lawson C. Health policy in Slovakia and the outcomes of health care reforms: 1989-2003. J Comp Policy Analysis. 2005;7(1):49-71. 